In vitro biological evaluation of new antimycobacterial salicylanilide-tuftsin conjugates

Zsuzsa Baranyai, Martin Krátký, Rudolf Vosátka, Eleonóra Szabó, Zsuzsanna Senoner, Sándor Dávid, Jiřina Stolař́ḱková, Jarmila Vinšová, Szilvia Bősze

European Journal of Medicinal Chemistry, 2017, 133, 152-173.

doi: 10.1016/j.ejmech.2017.03.047.

https://www.sciencedirect.com/science/article/pii/S0223523417302039?via\%3Dihub 


\title{
In vitro biological evaluation of new antimycobacterial salicylanilide- tuftsin conjugates
}

\author{
Zsuzsa Baranyai ${ }^{1}$, Martin Krátký ${ }^{2}$, Rudolf Vosátka ${ }^{2}$, Eleonóra Szabó ${ }^{3}$, Zsuzsanna Senoner $^{3}$, Sándor Dávid ${ }^{1,3}$, \\ Jiřina Stolař́iková ${ }^{4}$, Jarmila Vinšová ${ }^{2}$, and Szilvia Bősze ${ }^{1 *}$
}

${ }^{1}$ MTA-ELTE Research Group of Peptide Chemistry, Pázmány Péter Sétány 1/A, Budapest, H-1117, Hungary, P.O. Box 32, 1518 Budapest 112, Hungary; e-mail: bosze@elte.hu (Sz.B.); baranyaizsuzs@gmail.com (Zs.B.)

${ }^{2}$ Department of Organic and Bioorganic Chemistry, Faculty of Pharmacy, Charles University, Heyrovského 1203, 50005 Hradec Králové, Czech Republic; e-mail: martin.kratky@faf.cuni.cz (M.K.); vosatkar@faf.cuni.cz (R.V.); jarmila.vinsova@faf.cuni.cz (J.V.)

${ }^{3}$ Laboratory of Bacteriology, Korányi National Institute for Tuberculosis and Respiratory Medicine, Pihenő út 1, Budapest, H-1122, Hungary; e-mail: nora.szabo@koranyi.hu (E.Sz.); senonerzsuzsa@gmail.com (Zs.S.)

${ }^{4}$ Laboratory for Mycobacterial Diagnostics and Tuberculosis, Regional Institute of Public Health in Ostrava, Partyzánské náměstí 7, 70200 Ostrava, Czech Republic, e-mail: jirina.stolarikova@ @uova.cz (J.S.)

* Corresponding author: Szilvia Bősze: Pázmány Péter Sétány 1/A, Budapest, H-1117, Hungary, P.O. Box

32, 1518 Budapest 112, Hungary. e-mail: bosze@elte.hu, tel.: +36-372-2500 ext. 1736, fax: +36-372-26-20.

\begin{abstract}
Tuberculosis is caused by Mycobacterium tuberculosis, an intracellular pathogen that can survive in host cells, mainly in macrophages. An increase of multidrug-resistant tuberculosis qualifies this infectious disease a major public health problem worldwide. The cellular uptake of the antimycobacterial agents by infected host cells is limited. Our approach is to enhance the cellular uptake of the antituberculars by target cell-directed delivery using drug-peptide conjugates to achieve an increased intracellular efficacy. In this study, salicylanilide derivatives (2-hydroxy- $N$-phenylbenzamides) with remarkable antimycobacterial activity were conjugated to macrophage receptor specific tuftsin based peptide carriers through oxime bond directly or by insertion of a GFLG tetrapeptide spacer. We have found that the in vitro antimycobacterial activity of the salicylanilides against $M$. tuberculosis $\mathrm{H}_{37} \mathrm{Rv}$ is preserved in the conjugates. While the free drug was ineffective on infected macrophage model, the conjugates were active against the intracellular bacteria. The fluorescently labelled peptide carriers that were modified with different fatty acid side chains showed outstanding cellular uptake rate to the macrophage model cells. The conjugation of the salicylanilides to tuftsin based carriers reduced or abolished the in vitro cytostatic activity of the free drugs with the exception of the palmitoylated conjugates. The conjugates degraded in the presence of rat liver lysosomal homogenate leading to the formation of an oxime bond-linked salicylanilide-amino acid fragment as the smallest active metabolite.
\end{abstract}




\section{Keywords}

salicylanilide; tuftsin based carrier; fatty acid side chain; antimycobacterial activity; intracellular bacteria; cellular uptake

$\begin{array}{ll}\text { Abbreviations } & \\ \text { Ac: } & \text { acetylated } \\ \text { Aoa: } & \text { (aminooxy)acetylated } \\ \text { but: } & n \text {-butyl side chain } \\ \text { Cf: } & \text { labelled with 5(6)-carboxyfluorescein } \\ \text { dec: } & n \text {-decanoyl side chain } \\ \text { OT10: } & \text { dituftsin derivative, }[\mathrm{TKPKG}]_{2} \\ \text { OT20: } & \text { tetratuftsin derivative, }[\mathrm{TKPK}]_{4} \\ \text { pal: } & \text { palmitoyl side chain } \\ \text { SAL: } & \text { salicylanilide derivative } \\ \text { T5: } & \text { monotuftsin derivative, TKPKG }\end{array}$




\section{Introduction}

One third of the world's population is estimated to be infected with tuberculosis (TB), which is an infectious disease caused by the slow growing Mycobacterium tuberculosis bacteria. M. tuberculosis is mainly an intracellular pathogen; in the latent form of TB the bacteria can survive within the host cell phagocytes for many years. Latent TB is an asymptomatic phase of the disease, during this dormant phase the bacteria do not multiply but persist within their host cells (monocytes, macrophages). People infected with latent TB have a lifetime risk of $10 \%$ of developing active TB. However, persons with compromised immune systems have a much higher risk of falling ill [1]. The treatment of TB is long and the currently used antituberculars have serious side effects.

The increase of multidrug-resistant tuberculosis (MDR-TB) in the last decade is very alarming. MDRTB strains are resistant to at least isoniazid (INH) and rifampicin (RIF), the two most effective first-line antituberculars. Growing number of XDR-TB (extensively drug-resistant TB; resistant to INH, RIF, any fluoroquinolone, and one of the three second-line injectables, amikacin, capreomycin, or kanamycin) was also reported [1].

In addition, the appearance of a new emerging mycobacterium, Mycobacterium abscessus has been identified. M. abscessus is an intracellular pathogen that is the most chemotherapy-resistant rapid-growing mycobacterium. It is a common water contaminant, responsible for a wide spectrum of infectious diseases, chronic lung disease in patients with cystic fibrosis, post-traumatic wound infections, soft tissue infections and disseminated cutaneous diseases, mostly in patients with suppressed immune system. The treatment of M. abscessus infections is difficult, high rate of intrinsic resistance can occur to both antitubercular drugs and to most of the available antibiotics $[2,3,4,5]$.

There is an urgent need to try to overcome these threatening mycobacterial strains by the development of new potent antimycobacterial drugs with enhanced activity in the intracellular environment.

Salicylanilides (2-hydroxy- $N$-phenylbenzamides) have been the subject of interest in medicinal chemistry for many years. They have a wide variety of interesting biological activities, including antimycobacterial effects [6]. They have shown activity not only against classical M. tuberculosis $\mathrm{H}_{37} \mathrm{Rv}$, but also against atypical strains of mycobacteria, mainly Mycobacterium avium, M. fortuitum and M. kansassii where standard antituberculotics fail [6, 7]. Importantly, salicylanilides inhibit the growth of different MDR and XDR TB strains [8,9]. In our previous study we reported salicylanilide derivatives that are highly effective also against $M$. abscessus [9]. The structure-activity relationship studies suggest that among the big family of the different salicylanilides the derivatives substituted with halogens on both salicylic and aniline ring are the most potent ones against mycobacteria [6,9].

Salicylanilides have probably multiple mechanisms of action. They were identified as inhibitors of the two-component regulatory systems of bacteria, which is a signal transmission pathway involved in the maintenance of bacterial cell homeostasis and the expression of virulence factors [10]. Salicylanilides have displayed the ability to inhibit various bacterial enzymes, e.g., mycobacterial isocitrate lyase $[8,11,12,13$, 14] and methionine aminopeptidase [14].

Unfortunately, in many cases the outstanding antimycobacterial activity of the salicylanilide derivatives is overshadowed by their high or moderate cytotoxicity to mammalian cells (human monocytic cells) [9].

The design of peptide-based drug conjugates is one of the approaches that can promote increased drug specificity, where the peptide component serves as selective target and carrier to infected macrophages. With the drug delivery systems enhanced cellular uptake and bioavailability, controlled drug release and reduced side effects can be achieved. Receptor mediated endocytosis can enhance the intracellular elimination of $M$. 
tuberculosis $[15,16]$. Receptors that are expressed mainly on macrophages could be a proper target to achieve more efficient inhibition of $M$. tuberculosis from infected macrophages. In previous works tuftsin receptor is used for targeted drug delivery to macrophages $[17,18,19]$. It is estimated that there are 72000 tuftsin binding sites on the surface of phagocytic cells [20], therefore tuftsin can be a promising carrier peptide for targeted delivery into macrophages through receptor mediated internalization [17, 21].

Tuftsin is a natural tetrapeptide (human: TKPR; canine: TKPK) produced by enzymatic cleavage of the Fc-domain of the heavy chain of immunoglobulin $\mathrm{G}(\mathrm{IgG})$ by two enzymes, leukokininase and spleen tuftsin endocarboxypeptidase. This peptide activates several components of the immune system, including granulocytes and macrophages [22]. Tuftsin derivatives also stimulates phagocytosis and cell migration [23], human tuftsin and its analogues have a chemotactic effect on monocytes [24, 25].

During the past years, a new group of sequential oligopeptides based on tuftsin has been developed in our laboratory. The oligotuftsin derivatives consist of tandem pentapeptide repeat units $[\mathrm{TKPKG}]_{\mathrm{n}}(\mathrm{n}: 2,4,6$, 8) derived from the canine tuftsin sequence TKPK extended by a C-terminal Gly [26, 27]. These compounds are nontoxic, nonimmunogenic, biodegradable, and exhibit tuftsin-like biological properties, e.g. immunostimulatory activity and chemotactic activity on monocytes [28, 29]. The canine tuftsin TKPK where arginine is replaced by lysine that has also basic character has similar biological activities like the human tuftsin TKPR [30]. However, the second lysine residue in the sequence of TKPK can offer a new functional group for connection of a biologically active compound. With the addition of a glycine residue to the Cterminal of TKPK racemization free condensation of the fragments can be achieved to form larger oligomers [26]. Molecular modeling study suggested a flexible structure for oligotuftsin OT20 ([TKPKG] $]_{4}$ ), and also demonstrated fairly good solvent accessibility of the $\varepsilon$-amino group of each lysine residue, ${ }^{4} \mathrm{Lys}$ was the most accessible out of the eight Lys residues [26].

Modifying drug-peptide conjugates with fatty acids can be a promising tool to improve their activity. It was found that conjugation of fatty acids with different lengths modulated the antibacterial activity of cationic peptides and antimicrobial peptides [31,32]. Attaching a hydrophobic moiety to a drug-peptide conjugate can play an important role in the interaction of the drug and lipid membranes [33]. Palmitic, hexadecenoic, octadecenoic and tuberculostearic acids were found as the major fatty acid constituents of phospholipids of Mycobacteria [34]. Daptomycin is a decanoic acid containing lipopeptide antibiotic that displays rapid bactericidal activity against Gram-positive pathogens, including streptococci, methicillinresistant S. aureus, and vancomycin-resistant enterococci [35]. Daptomycin disrupts bacterial cell membrane function and permeability [36].

INH-tuftsin conjugates GTKPK(INH-CH$\left.{ }_{2}-\mathrm{CO}\right) \mathrm{G}$ and $\left[\mathrm{TKPK}\left(\mathrm{INH}-\mathrm{CH}_{2}-\mathrm{CO}\right) \mathrm{G}\right]_{4}$ were effective against M. tuberculosis and the minimal inhibitory concentration values were comparable to the free INH moiety [37]. Enhanced cellular uptake and significant inhibition of intracellular M. tuberculosis was performed by conjugation of new in silico identified drug candidate to [TKPKG] $]_{4}$ tuftsin derivative (TB5-OT20) [38]. Tuftsin based conjugates of pyridopyrimidine derivatives with in vitro antitubercular activity presented increased membrane affinity on lipid model systems [39]. Palmitoylated tuftsin conjugate of INH (palT5(INH) $)_{2}$, where T5 is TKPKG) and new in silico identified drug candidate (pal-T5(TB820) 2 ) found to be effective against susceptible and multiresistant $M$. tuberculosis strains with a relatively high in vitro selectivity [40, 41]. Free INH did not exhibit intracellular antitubercular activity, in contrast, its palT5(INH) $)_{2}$ conjugate significantly inhibited the intracellular $M$. tuberculosis [42]. The palmitoylated conjugates were encapsulated into PLGA (poly(lactide-co-glycolide)) nanoparticles with high encapsulation efficacy and the encapsulated compound showed high in vivo efficacy and low toxicity [41, 42]. 
In this study various tuftsin derivatives such as tetramer $[\mathrm{TKPKG}]_{4}(\mathrm{OT} 20)$, heterotrimer TKPR$[\text { TKPKG }]_{2}$ (TKPR-OT10), dimer [TKPKG $]_{2}$ (OT10) and monomer tuftsin derivatives TKPKG (T5), TKPR, TKPPR (tuftsin antagonist [43]) were used as carrier peptides. Tuftsin derivatives with modified Lys residues (e.g. introduction of palmitic acid, decanoic acid or butyric acid) were also studied. Modification with fatty acid chains can enhance the lipophilicity, membrane affinity and encapsulation efficacy [33, 41, 42]. Modified conjugable salicylanilides were attached to the tuftsin derivatives via oxime bond directly or by the insertion of a spacer between the drug molecule and the carrier. The oxime bond is chemically stable between $\mathrm{pH} 3$ and 8 [44], the incorporation of an enzymatic cleavable spacer between the drug and the carrier moiety might be necessary for the efficient drug release and activity. As spacer, the enzyme labile GFLG tetrapeptide was applied, which could be cleaved by the lysosomal cysteine protease, cathepsin B [45]. Here we report the synthesis, chemical characterization, in vitro extracellular and intracellular antimycobacterial activity, cytotoxic and cytostatic activity, cellular uptake, membrane integrity studies and lysosomal degradation of salicylanilide-tuftsin conjugates. 


\section{Results and Discussion}

\subsection{Chemistry}

\subsubsection{Synthesis of the salicylanilide derivatives SAL1-3}

Salicylanilides were prepared by the reaction of the appropriate substituted salicylic acids and the substituted anilines in the presence of phosphorus trichloride ( 0.5 eq.) in chlorobenzene (Scheme 1). The reaction was carried out in a microwave reactor for $22 \mathrm{~min}$ to reflux [46]. The yields ranged from 6-7 \%. The yields are low due to the predominant formation of Schiff bases instead of amide. In the case of the synthesis of SAL1 and SAL2, the resulting Schiff base (main product) can react with other molecules of 4acetylaniline to form more complex Schiff bases.<smiles>[R]c1ccc(O)c(C(=O)O)c1</smiles><smiles>CC(=O)c1ccc(N)cc1</smiles>

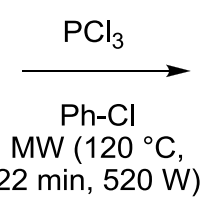<smiles>CC(=O)c1ccc(N=Cc2ccc(N)cc2)cc1</smiles>

main product<smiles>[R]c1ccc(O)c(C(=O)Nc2ccc(C(C)=O)cc2)c1</smiles>

SAL2 $(R=B r)$

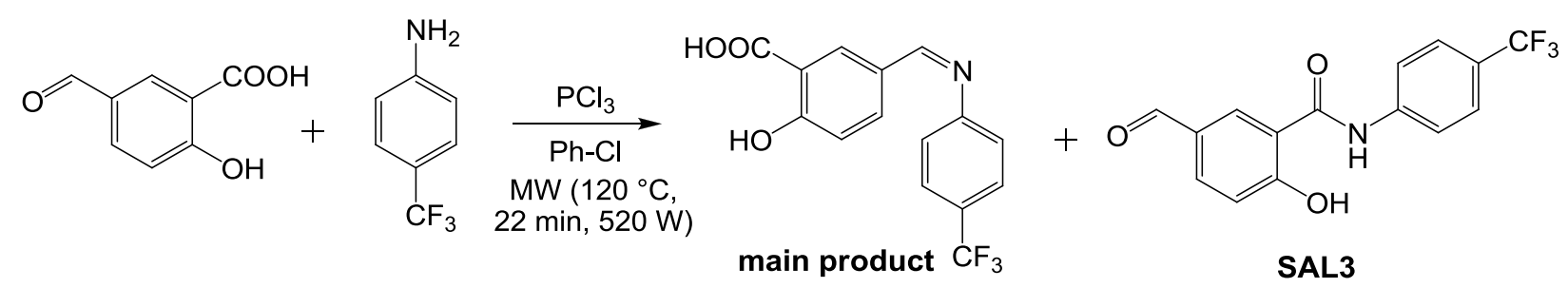

Scheme 1. Synthesis of conjugable salicylanilides SAL1-3 (Ph-Cl: chlorobenzene).

\subsubsection{Synthesis of the tuftsin derivatives}

Tuftsin derivatives were synthesized using the standard Fmoc/t $\mathrm{Bu}$ strategy. The $\mathrm{C}$-terminal of the peptides was obtained in amide or carboxyl form after cleavage. In the short name of the peptides or conjugates only the carboxyl form C-terminal is indicated, otherwise the C-terminal of the peptides or conjugates are in amide form. The synthesis of the tuftsin derivatives without side chain modification is summarized in the Supporting Information Scheme S1.

In the case of the peptides with modified Lys side chain the routinely used Fmoc-Lys-tertbutoxycarbonyl-OH (Fmoc-Lys(Boc)-OH) was replaced by Fmoc-Lys(Dde)-OH in the appropriate position and after the selective removal of the Dde group with a solution of $2 \%$ hydrazine hydrate in DMF [47] the synthesis was carried on with the desired modification (coupling of fatty acids, Boc-Aoa-OH or 5(6)carboxyfluorescein). The schematic route of the synthesis of the tuftsin derivatives with side chain modification is summarized in Scheme 2.

The N-terminal of most of the peptides were (aminooxy)acetylated for the conjugation (Aoa-tuftsin derivatives). Control peptides with acetylated N-termini were also prepared (Ac-tuftsin derivatives). Fluorescently labelled peptides with 5(6)-carboxyfluorescein at the N-termini was also synthesized (Cftuftsin derivatives). All peptides were cleaved from the resin with TFA in the presence of appropriate scavengers. The Aoa-peptides were used for conjugation without purification. The acetylated control peptides and the fluorescently labelled peptides were purified using semi-preparative RP-HPLC. All tuftsin 
derivatives were chemically characterized by analytical RP-HPLC, mass spectrometry (Supporting Information Table S1) and amino acid analysis (data not shown).

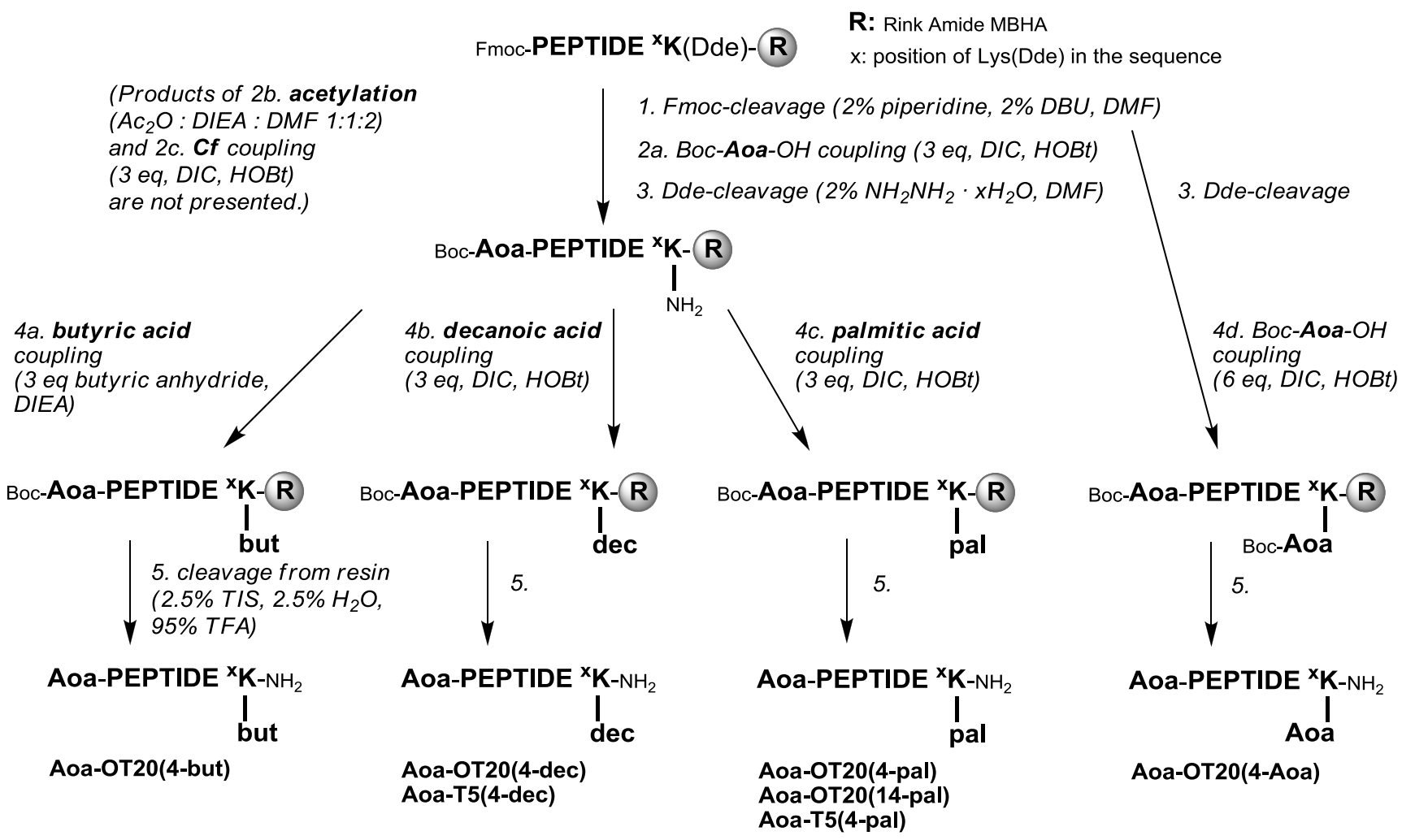

Scheme 2. Schematic route of the synthesis of the tuftsin derivatives with side chain modification.

\subsubsection{Synthesis of the salicylanilide-tuftsin conjugates}

SAL1, SAL2 and SAL3 were conjugated to the (aminooxy)acetylated tuftsin derivatives by oxime ligation, which was carried out under acidic condition $(\mathrm{pH} 4.5)$ in a mixture of sodium acetate buffer solution and 2-methoxyethanol (Scheme 3A). In the case of SAL3 the reaction occurred faster due to the higher reactivity of the aldehyde group compared to the acetyl group. The conjugation was monitored using analytical RP-HPLC (Supporting Information Figure S1). The general structures of the synthesized conjugates are schematically represented in Scheme 3B. The schematic figure of all of the salicylanilidetuftsin conjugates are represented in Supporting Information Figure S2. The conjugates were purified using semi-preparative RP-HPLC and chemically characterized by analytical RP-HPLC, mass spectrometry and amino acid analysis. All purified conjugates demonstrated a single peak on analytical RP-HPLC with a mass coinciding with the theoretically calculated molecular mass (Supporting Information Table S2). The amino acid composition of the conjugates was proved by amino acid analysis where the accuracy was less than 5\% (data not shown).

The stability of the conjugates was investigated in the condition of the in vitro studies. The stability was studied in DMSO at $4{ }^{\circ} \mathrm{C}$, in Sula semisynthetic medium (pH 6.5) at $37^{\circ} \mathrm{C}$, in serum free RPMI-1640 cell culture medium at $37{ }^{\circ} \mathrm{C}$, and in complete RPMI-1640 cell culture medium at $37^{\circ} \mathrm{C}$ using analytical RPHPLC and mass spectrometry (methods and conditions are in the Supporting Information). The compounds were stable in DMSO at $4{ }^{\circ} \mathrm{C}$ at least for 3 weeks (Figure S3). They are mostly stable in Sula medium after 4 weeks of incubation, only approximately $5 \%$ of the conjugate was decomposed to the free salicylanilide and 2-hydroxyacetyl-tuftsin derivative (Figure S4-S5). The compounds were stable in serum free and in complete cell culture medium at $37^{\circ} \mathrm{C}$ at least for 1 week and 1 day respectively (Figure S6-S7). 
<smiles>[R]c1ccc(O)c(C(=O)Nc2ccc(C(C)=O)cc2)c1</smiles>

SAL1-2<smiles>O=Cc1ccc(O)c(C(=O)Nc2ccc(C(F)(F)F)cc2)c1</smiles>

SAL3

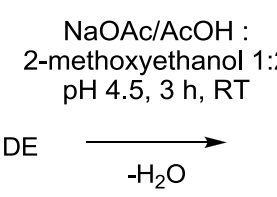

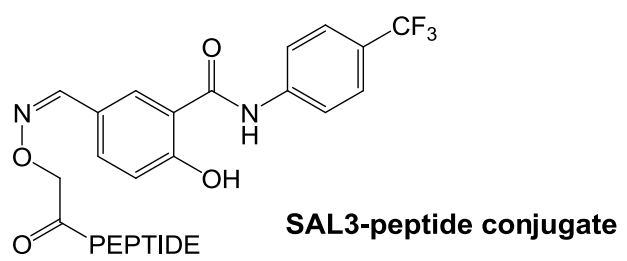

B
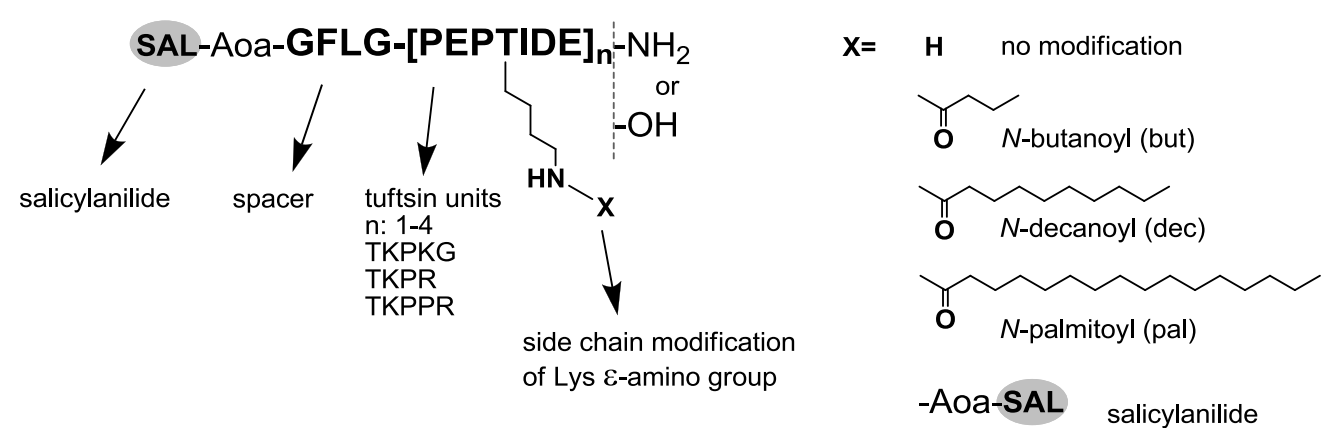

Scheme 3. (A) Conjugation of salicylanilide derivatives to (aminooxy)acetylated tuftsin derivatives and (B) the summarized schematic structure of the salicylanilide-tuftsin conjugates.

\subsubsection{Synthesis of salicylanilide-amino acid derivatives}

To investigate the in vitro activity of the smallest metabolites produced during the degradation in the lysosomal homogenate, SAL2-Aoa-Thr-OH and SAL2-Aoa-Gly-OH were synthesized. To estimate lipophilicity profile for tuftsin conjugates three salicylanilide-amino acid derivatives were used as reference compounds with calculated $\log \mathrm{P}$ values (Table S3): SAL2-Aoa-Thr-OH, SAL2-Aoa-Gly-OH and HLys(SAL2-Aoa)-OH (SAL2 is on the $\varepsilon$-amino group of the lysine). The amino acids were functionalized with (aminooxy)acetyl group on solid phase. After cleavage from the resin Aoa-Thr-OH, Aoa-Gly-OH and H-Lys(Aoa)-OH (Table S1) was conjugated to SAL2 salicylanilide derivative as described above. The SAL2-amino acid derivatives were purified using semi-preparative RP-HPLC and chemically characterized by analytical RP-HPLC and mass spectrometry (Table S2).

\subsubsection{Lipophilicity profile of the salicylanilide derivatives and salicylanilide-peptide conjugates}

Lipophilicity is an important physicochemical parameter regarding the interaction between an active compound and membrane structures of the cells. It has been studied that the retention of a compound on reversed-phase chromatographic columns (C18) resulted in correlation with the lipophilicity of the compounds $[48,49]$. To predict lipophilicity of peptides experimentally or semiempirically is difficult, since amino acid side chains contain charged or uncharged polar and non-polar groups and have a range of size and flexibility. However, retention time (Rt) on the reversed phase columns may provide relevant information about the lipophilicity range of compounds such as drug candidates and their peptide conjugates $[50,51]$. The behaviour of a compound in RP-HPLC system depends on its interactions with the non-polar stationary phase: the more lipophilic a compound is, the stronger its retention on the column. 
The lipophilicity of the representative compounds was estimated by the retention time acquired on analytical RP-HPLC system using a C18 column and the same gradient for each compounds (Figure 1, Table S3). Parent salicylanilides from our previous work (2a-d) [9] are also presented for the comparison with the conjugable salicylanilide derivatives (SAL1-3). The oxime bond containing salicylanilide-amino acid derivatives detected during the lysosomal hydrolysis of the conjugates and representative conjugates are also included. The calculated $\log P$ values of the reference salicylanilide derivatives and salicylanilide-amino acid derivatives obtained by CS ChemOffice Ultra ver. 11.0 are also presented (Figure 1, Table S3).

According to the retention time of the compounds, the parent salicylanilides are the most lipophilic molecules followed by the conjugable salicylanilides (Figure 1, Table S3). The salicylanilide-amino acid derivatives are less lipophilic than the conjugable salicylanilides. Tuftsin derivatives are peptides with charged amino acid side chain moieties (Lys, Arg) therefore they possess high hydrophilic character. The conjugation of the salicylanilide to peptide made the conjugates more lipophilic than the carrier tuftsin peptide itself. The longer, tetratuftsin-conjugate is more hydrophilic, than the di- or monotuftsin derivatives (SAL2-Aoa-OT20 Rt: $14.3 \mathrm{~min}$, SAL2-Aoa-OT10 Rt: $14.9 \mathrm{~min}$, SAL2-Aoa-T5 $15.6 \mathrm{~min}$ ). Conjugate with the GFLG spacer built up by non-polar amino acids has more lipophilic character than its analogue without the spacer (SAL2-Aoa-OT20 Rt: $14.3 \mathrm{~min}$, SAL2-Aoa-GFLG-OT20 Rt: $15.7 \mathrm{~min}$ ). The different fatty acid side chain modifications also altered the lipophilicity of the conjugate as was expected; the longer the fatty acid is, the more lipophilic the molecule (SAL2-Aoa-OT20: Rt: $14.3 \mathrm{~min}$, SAL2-OT20(4-but) Rt:14.7 min, SAL2-Aoa-OT20(4-dec) Rt: $16.4 \mathrm{~min}$ SAL2-Aoa-OT20(4-pal) Rt: $18.4 \mathrm{~min}$ ). The position of the palmitic acid side chain influences the lipophilicity. In the SAL2-Aoa-OT20(4-pal) conjugate (Rt: 18.4 min), where the non-polar moieties such as the SAL2 and the palmitoyl side chain are closer to each other, the retention time is higher than in the case of the SAL2-Aoa-OT20(14-pal) (Rt: $17.3 \mathrm{~min}$ ), where the palmitic acid is further from the SAL2 molecule in the sequence. The effect of the fatty acids is more significant in the case of the monotuftsin conjugate; SAL2-Aoa-T5(4-dec) has similar lipophilicity as the SAL2, moreover the SAL2-Aoa-T5(4-pal) monotuftsin conjugate is more lipophilic than the SAL2 and any other presented salicylanilides. The number of the drug molecules in the conjugate also influences the lipophilicity, the two SAL2 containing conjugate has higher lipophilicity than the one SAL2 containing conjugate (SAL2-AoaOT20(4-SAL2-Aoa) Rt: $16.3 \mathrm{~min}$, SAL2-Aoa-OT20 Rt: $14.3 \mathrm{~min}$ ). 


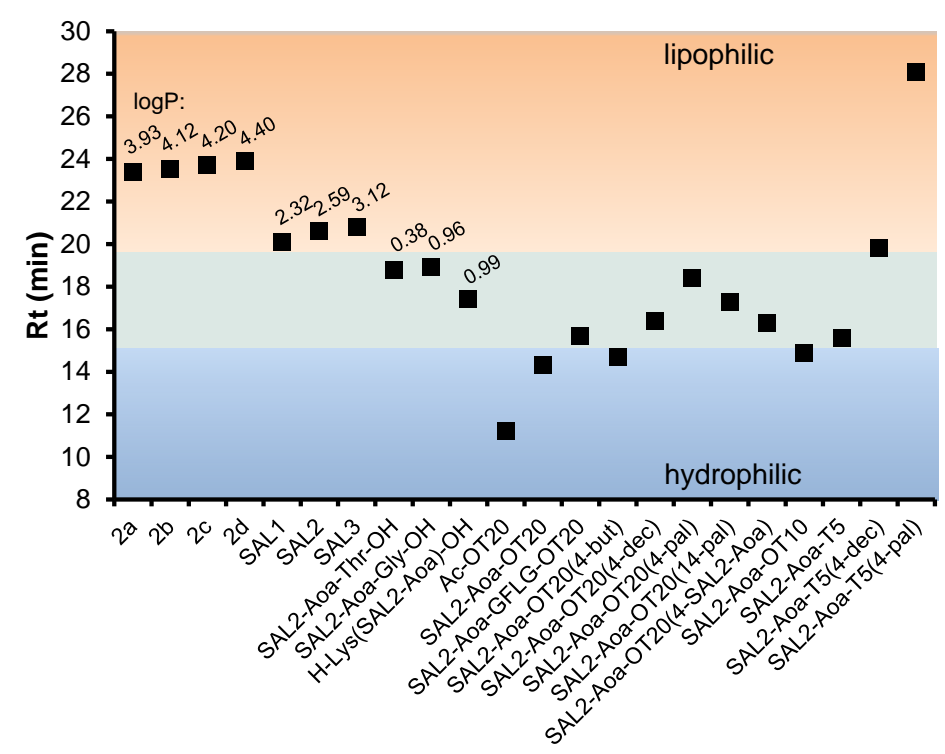

Figure 1. Retention time of parent salicylanilides, conjugable salicylanilides, salicylanilide amino acid derivatives (metabolites detected during lysosomal degradation) and salicylanilide-peptide conjugates. The calculated $\log \mathrm{P}$ value is indicated in the case of the parent salicylanilides, conjugable salicylanilides and metabolites using the program CS ChemOffice Ultra ver. 11.0 (CambridgeSoft, Cambridge, MA, USA). $\operatorname{LogP}$ was calculated for the amino acid derivatives with protonated amino group and/or deprotonated carboxylic group. The $\mathrm{C}$-terminal of the peptides is in amide form, $\mathrm{Ac}=$ acetyl, retention time (Rt) was obtained on Exformma HPLC system; column: Agilent Zorbax SB-C18, $5 \mu \mathrm{m}, 4.6 \mathrm{mmx} 150 \mathrm{~mm}, 100 \AA$; gradient: $0 \min 0 \%$ B, $5 \min 0 \%$ B, $15 \min 60 \%$ B, $25 \min 100 \%$ B; eluents: $0.1 \%$ TFA in water (A) and $0.1 \%$ TFA in acetonitrile-water (80:20, v/v) (B); flow rate: $1 \mathrm{~mL} / \mathrm{min}$; detection at $220 \mathrm{~nm}$.

\subsection{In vitro antimycobacterial activity}

The free salicylanilide derivatives and the salicylanilide-tuftsin conjugates were evaluated for their in vitro antimycobacterial activity against two strains of slowly growing $M$. tuberculosis: the sensitive $\mathrm{H}_{37} \mathrm{Rv}$ and the multidrug resistant A8 MDR strain (resistant to both INH and RIF, two first-line antituberculars) and against a fast growing mycobacterium, the M. abscessus strain. Isoniazid (INH), ciprofloxacin (CIPX) and gentamicin (GEN) as antimycobacterial active drugs were involved for comparison. Table 1 reports the obtained minimum inhibitory concentrations (MICs). The inhibition was confirmed using Löwenstein-Jensen solid media and the colony forming units (CFU) were determined. The colony forming units are presented in the Supporting Information Table S4.

The MIC values of previously published parent salicylanilides are presented in Table 2 for comparison [9]. These parent salicylanilides have outstanding in vitro antimycobacterial activity. They have MICs from 1.4-2.8 $\mu \mathrm{M}$ against M. tuberculosis $\mathrm{H}_{37} \mathrm{Rv}$ and $\mathrm{A} 8 \mathrm{MDR}$ and their MICs against M. abscessus range from 3.2-13.9 $\mu \mathrm{M}$. The introduction of the carbonyl group into the molecule reduced their in vitro antimycobacterial activity. In the parent salicylanilides both the salicylic acid ring and the aniline ring contain halogen substituents. In SAL1 and SAL2 the halogen on the aniline ring was replaced by an acetyl group though SAL1 and SAL2 still have an appropriate inhibition activity against M. tuberculosis $\mathrm{H}_{37} \mathrm{Rv}$ (8.6 and $7.5 \mu \mathrm{M}$ respectively). Their MIC values against the resistant strain are slightly higher (SAL1 17.3 $\mu \mathrm{M}$, SAL2 $15.0 \mu \mathrm{M}$ ) than the MIC values of the parent molecules. Against $M$. abscessus the new salicylanilides SAL1 and SAL2 are effective with higher MIC values (34.5 and $59.8 \mu \mathrm{M}$ respectively). In the case of SAL3, where the halogen group of the salicylic acid ring was replaced by an aldehyde group, the in vitro 
antimycobacterial activity decreased significantly against all the three bacterial strain compared to the parent salicylanilides and to SAL1 and SAL2.

The in vitro antimycobacterial activity of the salicylanilides is preserved in the conjugates against $M$. tuberculosis $\mathrm{H}_{37} \mathrm{Rv}$ although their MIC values (20.3-186.5 $\left.\mu \mathrm{M}\right)$ are higher than the MIC of the free salicylanilides $(7.5-25.9 \mu \mathrm{M})$. There is no difference in the activity between the different salicylanilide containing OT20 or OT20(4-pal) conjugates. In terms of the peptide length, SAL2-Aoa-OT20 showed better activity than the shorter SAL2-Aoa-OT10 and the shortest SAL2-Aoa-T5 showed the best efficacy with very low MIC values $(21.8 \mu \mathrm{M})$ among these conjugates. The incorporation of the enzyme labile GFLG spacer has no significant benefit in the antimycobacterial activity of the conjugates, the MIC values of the one tuftsin unit containing conjugates with or without spacer is mostly the same. In the case of tetratuftsin derivative containing conjugate the presence of the GFLG spacer reduce its activity (SAL2-Aoa-OT20 with MIC of $81.5 \mu \mathrm{M}$ vs. SAL2-Aoa-GFLG-OT20 with MIC of $141.5 \mu \mathrm{M}$ ). Among all the conjugates the short tuftsin derivative containing conjugates (namely SAL2-Aoa-T5, SAL2-Aoa-T5-OH, SAL2-Aoa-TKPR-OH and SAL2-Aoa-TKPPR-OH) and their analogues with GFLG spacer showed outstanding in vitro antimycobacterial activity against $M$. tuberculosis $\mathrm{H}_{37} \mathrm{Rv}$. The SAL2-Aoa-T5 with amide on the C-terminal was three-times more effective than its analogue SAL2-Aoa-T5-OH with C-terminal carboxyl group. The most effective conjugates are the SAL2-Aoa-TKPPR-OH (MIC value of $20.3 \mu \mathrm{M}$ ) and SAL2-Aoa-T5 (MIC value of $21.8 \mu \mathrm{M})$. Their MIC value is only three-times higher than the MIC value of the free salicylanilide SAL2. Both conjugates that contain two molecules of SAL2, i.e. SAL2-Aoa-OT20(4-SAL2-Aoa) and TKPR-OT10(8-SAL2-Aoa; 13-SAL2-Aoa) were also very effective against M. tuberculosis $\mathrm{H}_{37} \mathrm{Rv}$ with MIC values of 42.2 and $34.8 \mu \mathrm{M}$ respectively. From the perspective of the length of the fatty acid, butyric acid and decanoic acid in SAL2-Aoa-OT20(4-but) (MIC of $63.4 \mu \mathrm{M}$ ) and SAL2-Aoa-OT20(4-dec) (MIC of 76.7 $\mu \mathrm{M}$ ) slightly improved the activity of SAL2-Aoa-OT20 (MIC of $81.5 \mu \mathrm{M}$ ), their analogue without fatty acid. In the case of the palmitoylated conjugates, a slight influence of the position of palmitic acid side chain can be observed in the activity. SAL2-Aoa-OT20(4-pal) has higher MIC value $(92.9 \mu \mathrm{M})$ than SAL2-Aoa-OT20, on the contrary SAL2-Aoa-OT20(14-pal) has slightly lower MIC value $(74.3 \mu \mathrm{M})$ than SAL2-Aoa-OT20 without fatty acid. The presence of the fatty acids has a higher influence on the activity of the shorter conjugates. In the case of SAL2-Aoa-T5(4-dec) (MIC of 186.5 $\mu \mathrm{M}$ ) and SAL2-Aoa-T5(4-pal) (MIC of 173.1 $\mu \mathrm{M})$ the presence of these fatty acids highly reduced their activity compared to their analogue SAL2-Aoa-T5 without fatty acid (MIC of $21.8 \mu \mathrm{M}$ ). The smallest metabolites produced during lysosomal degradation, SAL2-Aoa-Thr-OH and SAL2-Aoa-Gly-OH have a low activity with high MIC values (393.5 and $215.4 \mu \mathrm{M}$ respectively).

In the aspect of the MIC values calculated to the drug contents of the conjugates, most of the OT20 conjugates were effective at $25 \mu \mathrm{g} / \mathrm{mL}$ drug content concentration, which is only 10-times higher than the MIC of the free SAL1 and SAL2 molecules $(2.5 \mu \mathrm{g} / \mathrm{mL})$. However, among the short tuftsin derivative containing conjugates we can find compounds that have even lower MIC values calculated to drug content, between 6.8 and $10.6 \mu \mathrm{g} / \mathrm{mL}$ (SAL2-Aoa-T5, SAL2-Aoa-GFLG-T5, SAL2-Aoa-GFLG-TKPR-OH, SAL2Aoa-TKPPR-OH and SAL2-Aoa-GFLG-TKPPR-OH).

The short tuftsin derivative containing conjugates that showed outstanding activity against $M$. tuberculosis $\mathrm{H}_{37} \mathrm{Rv}$ sensitive strain were selected to be measured on M. tuberculosis A8 MDR strain. These conjugates can inhibit the resistant bacteria only at the highest concentration tested, at $100 \mu \mathrm{g} / \mathrm{mL}(73.5$ 112.4 $\mu \mathrm{M}$ ). These MIC values are 2-5-times higher than their MIC values against the sensitive strain. In the aspect of the drug content, their average MIC value calculated to the drug content is $31 \mu \mathrm{g} / \mathrm{mL}$, which is 6 times higher than the MIC value of the free drug SAL2 $(5 \mu \mathrm{g} / \mathrm{mL})$. 
Most of the conjugates were active also against M. abscessus. They possessed MIC values between 40.8 and $224.8 \mu \mathrm{M}$. The salicylanilide-OT20 conjugates were the most effective against this strain. The SAL1-Aoa-OT20 $(\mathrm{MIC}=41.5 \mu \mathrm{M})$ and SAL2-Aoa-OT20 $(\mathrm{MIC}=40.8 \mu \mathrm{M})$ has similar activity as the free SAL1 $(\mathrm{MIC}=34.5 \mu \mathrm{M})$ and SAL2 $(\mathrm{MIC}=59.8 \mu \mathrm{M})$, and interestingly SAL3-Aoa-OT20 $(\mathrm{MIC}=41.2 \mu \mathrm{M})$ is three-times more effective than the free salicylanilide SAL3 with MIC of $129.4 \mu \mathrm{M}$. The other tetratuftsin derivative conjugates with spacer, fatty acid side chain or second salicylanilide (SAL2-Aoa-GFLG-OT20, SAL2-Aoa-OT20(4-but), SAL2-Aoa-OT20(4-dec), SAL1-Aoa-OT20(4-pal), SAL2-Aoa-OT20(4-pal), SAL2-Aoa-OT20(14-pal) and SAL2-Aoa-OT20(4-SAL2-Aoa)) acted similarly with MICs between 70.4 and $79.3 \mu \mathrm{M}$. Having two molecules of salicylanilide in the conjugate showed no significant advantage against M. abscessus. The MIC of SAL2-Aoa-OT20(4-SAL2-Aoa) $(70.4 \mu \mathrm{M})$ is slightly lower than the MIC of TKPR-OT10(8-SAL2-Aoa; 13-SAL2-Aoa) $(86.9 \mu \mathrm{M})$. The dituftsin derivative containing conjugate SAL2Aoa-OT10 had fairly good activity (MIC of $56.0 \mu \mathrm{M}$ ). The shortest peptide containing conjugates were the least effective with MICs ranged from 146.9-224.8 $\mu \mathrm{M}$. The incorporation of GFLG spacer made the conjugates slightly more active. The presence of fatty acid side chain in the T5 containing conjugates had no significant influence on the activity against M. abscessus. According to the MIC values calculated to the drug content, the SAL1-3-Aoa-OT20 conjugates ( MIC $_{\text {drug content }}$ is around $13 \mu \mathrm{g} / \mathrm{mL}$ ) were as effective or even more effective than the free SAL1-3 molecules (MIC within the range of 10-40 $\mu \mathrm{g} / \mathrm{mL}$ ). The other OT20 derivatives with a spacer or fatty acid side chain have MIC values calculated to the drug content around 25 $\mu \mathrm{g} / \mathrm{mL}$ and the average value of the short tuftsin derivative containing conjugates is $60 \mu \mathrm{g} / \mathrm{mL}$. 
Table 1. Antimycobacterial activity of the salicylanilides and the salicylanilide-tuftsin conjugates

\begin{tabular}{|c|c|c|c|c|c|c|c|c|c|}
\hline \multirow[b]{2}{*}{ compound, conjugate code ${ }^{a}$} & \multicolumn{3}{|c|}{ M. tuberculosis $\mathrm{H}_{37} \mathrm{Rv}$} & \multicolumn{3}{|c|}{ M. tuberculosis A8 MDR } & \multicolumn{3}{|c|}{ M. abscessus } \\
\hline & $\begin{array}{c}\text { MIC }^{b} \\
\gamma(\mu \mathrm{g} / \mathrm{mL})\end{array}$ & $\begin{array}{c}\text { MIC }_{\text {drug }} \\
\text { content } \\
(\mu \mathrm{g} / \mathrm{mL})\end{array}$ & $\begin{array}{l}\text { MIC } \\
(\mu \mathrm{M})\end{array}$ & $\begin{array}{c}\text { MIC }^{b} \\
\gamma(\mu \mathrm{g} / \mathbf{m L})\end{array}$ & $\begin{array}{c}\text { MIC }_{\text {drug }} \\
\text { content } \\
(\mu \mathrm{g} / \mathrm{mL})\end{array}$ & $\begin{array}{l}\text { MIC } \\
(\mu \mathrm{M})\end{array}$ & $\begin{array}{c}\text { MIC }^{b} \\
\gamma(\mu \mathrm{g} / \mathrm{mL})\end{array}$ & $\begin{array}{c}\text { MIC }_{\text {drug }} \\
\text { content } \\
(\mu \mathrm{g} / \mathrm{mL})\end{array}$ & $\begin{array}{l}\text { MIC } \\
(\mu \mathrm{M})\end{array}$ \\
\hline $\operatorname{control}^{d}$ & $\begin{array}{c}\text { no } \\
\text { inhibition }\end{array}$ & - & - & $\begin{array}{c}\text { no } \\
\text { inhibition }\end{array}$ & - & - & $\begin{array}{c}\text { no } \\
\text { inhibition }\end{array}$ & - & - \\
\hline $\mathrm{INH}^{e}$ & 0.16 & 0.16 & 1.17 & 1 & 1 & 7.3 & 40 & 40 & 291.8 \\
\hline SAL1 & 2.5 & 2.5 & 8.6 & 5 & 5 & 17.3 & 10 & 10 & 34.5 \\
\hline SAL2 & 2.5 & 2.5 & 7.5 & 5 & 5 & 15.0 & 20 & 20 & 59.8 \\
\hline SAL3 & 8 & 8 & 25.9 & 20 & 20 & 64.7 & 40 & 40 & 129.4 \\
\hline SAL1-Aoa-OT20 & 200 & 24.1 & 83.0 & nd & nd & nd & 100 & 12.0 & 41.5 \\
\hline SAL2-Aoa-OT20 & 200 & 27.3 & 81.5 & nd & nd & nd & 100 & 13.6 & 40.8 \\
\hline SAL3-Aoa-OT20 & $200^{f}$ & 25.5 & 82.4 & nd & nd & nd & 100 & 12.7 & 41.2 \\
\hline SAL2-Aoa-GFLG-OT20 & 400 & 47.3 & 141.5 & nd & nd & nd & 200 & 23.6 & 70.7 \\
\hline SAL2-Aoa-OT20(4-but) & 160 & 21.2 & 63.4 & nd & nd & nd & 200 & 26.5 & 79.3 \\
\hline SAL2-Aoa-OT20(4-dec) & $200^{f}$ & 25.6 & 76.7 & nd & nd & nd & 200 & 25.6 & 76.7 \\
\hline SAL1-Aoa-OT20(4-pal) & $>250^{g}$ & 27.4 & 94.5 & nd & nd & nd & $>200^{g}$ & 21.9 & 75.6 \\
\hline SAL2-Aoa-OT20(4-pal) & 250 & 31.0 & 92.9 & nd & nd & nd & $>200^{g}$ & 24.8 & 74.3 \\
\hline SAL2-Aoa-OT20(14-pal) & $200^{f}$ & 24.8 & 74.3 & nd & nd & nd & 200 & 24.8 & 74.3 \\
\hline SAL2-Aoa-OT20(4-SAL2-Aoa) & 120 & 28.2 & 42.2 & nd & nd & nd & 200 & 47.0 & 70.4 \\
\hline SAL2-Aoa-OT10 & 250 & 58.4 & 174.9 & nd & nd & nd & 80 & 18.7 & 56.0 \\
\hline TKPR-OT10(8-SAL2-Aoa; 13-SAL2-Aoa) & 80 & 23.2 & 34.8 & nd & nd & nd & 200 & 58.1 & 86.9 \\
\hline SAL2-Aoa-T5 & 20 & 7.3 & 21.8 & 100 & 36.4 & 108.9 & 160 & 58.3 & 174.3 \\
\hline SAL2-Aoa-GFLG-T5 & 40 & 10.3 & 31.0 & 100 & 25.9 & 77.4 & 200 & 51.7 & 154.8 \\
\hline SAL2-Aoa-T5(4-dec)- $\mathrm{NH}_{2}$ & $200^{f}$ & 62.3 & 186.5 & nd & nd & nd & 200 & 62.3 & 186.5 \\
\hline SAL2-Aoa-T5(4-pal)- $\mathrm{NH}_{2}$ & $200^{f}$ & 57.9 & 173.1 & nd & nd & nd & 200 & 57.9 & 173.1 \\
\hline SAL2-Aoa-T5-OH & 60 & 21.8 & 65.3 & 100 & 36.4 & 108.8 & 200 & 72.7 & 217.7 \\
\hline SAL2-Aoa-GFLG-T5-OH & 60 & 15.5 & 46.4 & 100 & 25.8 & 77.3 & 200 & 51.7 & 154.6 \\
\hline SAL2-Aoa-TKPR-OH & 40 & 15.0 & 45.0 & 100 & 37.6 & 112.4 & 200 & 75.1 & 224.8 \\
\hline SAL2-Aoa-GFLG-TKPR-OH & 40 & 10.6 & 31.6 & 100 & 26.4 & 79.1 & 200 & 52.9 & 158.2 \\
\hline SAL2-Aoa-TKPPR-OH & 20 & 6.8 & 20.3 & 100 & 33.9 & 101.3 & 200 & 67.7 & 202.7 \\
\hline SAL2-Aoa-GFLG-TKPPR-OH & 40 & 9.8 & 29.4 & 100 & 24.6 & 73.5 & 200 & 49.1 & 146.9 \\
\hline SAL2-Aoa-Thr-OH & $200^{f}$ & 131.5 & 393.5 & nd & nd & nd & nd & nd & nd \\
\hline SAL2-Aoa-Gly-OH & $100^{f}$ & 72.0 & 215.4 & nd & nd & nd & nd & nd & nd \\
\hline
\end{tabular}

${ }^{a}$ The $\mathrm{C}$-terminal of the peptides is in amide form if it is not indicated otherwise, the peptides with carboxylic C-terminal is always indicated with -OH.

${ }^{b}$ MIC (minimal inhibitory concentration) was determined on the M. tuberculosis $\mathrm{H}_{37} \mathrm{Rv}$, MDR-TB strain A8 (4 weeks) and M. abscessus strain (1 week) in Sula semisynthetic medium, pH 6.5. To confirm the growth inhibition, CFU (colony forming unit) was determined on Löwenstein-Jensen solid media, data are shown in Supporting Information Table S4.

${ }^{c}$ Calculated to drug content: $\mathrm{MIC}_{\text {drug content }}(\mu \mathrm{g} / \mathrm{mL})=\left(\mathrm{MIC}(\mu \mathrm{M}) \times \mathrm{M}_{\mathrm{av} \text { SAL }}(\mathrm{g} / \mathrm{mol}) \times \mathrm{n}\right) / 1000$, where $\mathrm{M}_{\mathrm{av}}$ SAL: molar mass of SAL; $\mathrm{n}$ : number of SAL in the conjugate.

${ }^{d}$ As positive control, bacteria were inoculated in the absence of drugs.

${ }^{e} \mathrm{INH}$ : isoniazid, as a control drug. The MIC values against $M$. abscessus of the control drugs CIPX and GEN were $40 \mu \mathrm{g} / \mathrm{mL}(291.8 \mu \mathrm{M}), 1 \mu \mathrm{g} / \mathrm{mL}$ $(3.0 \mu \mathrm{M})$ and $5 \mu \mathrm{g} / \mathrm{mL}(10.5 \mu \mathrm{M})$ respectively [9].

${ }^{f}$ Data are extrapolated from the data determined after 21 days of incubation.

${ }^{g}$ At this concentration the conjugates were able to reduce the CFU, but their MIC value is probably higher than the measured highest concentration. 
Table 2. In vitro antimycobacterial activity of the previously published parent salicylanilide derivatives [9], their cytostatic activity $(24 \mathrm{~h})$ on MonoMac6 and HepG2 cells and selectivity indexes calculated for $M$. tuberculosis $\mathrm{H}_{37} \mathrm{Rv}$<smiles>[R]c1ccc(NC(=O)c2cc([R])ccc2O)cc1</smiles>

\begin{tabular}{|c|c|c|c|c|c|c|c|c|c|}
\hline \multirow[b]{2}{*}{$\operatorname{code}^{a}$} & \multirow[b]{2}{*}{$\mathbf{R}^{1}$} & \multirow[b]{2}{*}{$\mathbf{R}^{2}$} & \multirow[b]{2}{*}{$\begin{array}{l}\text { M. tuberculosis } \\
\mathbf{H}_{37} \mathbf{R v} \\
\mathbf{M I C}(\boldsymbol{\mu M})\end{array}$} & \multirow[b]{2}{*}{$\begin{array}{l}\text { M. tuberculosis } \\
\text { A8 MDR } \\
\text { MIC ( } \boldsymbol{\mu M}) \text { [9] }\end{array}$} & \multirow[b]{2}{*}{$\begin{array}{c}\text { M. abscessus } \\
\text { MIC }(\boldsymbol{\mu M})[9]\end{array}$} & \multicolumn{2}{|c|}{ MonoMac6 } & \multicolumn{2}{|c|}{ HepG2 } \\
\hline & & & & & & $\begin{array}{l}\mathrm{IC}_{50} \\
(\mu \mathrm{M})\end{array}$ & $\begin{array}{l}\mathrm{SI}^{b} \text { for } M . \\
\text { tuberculosis } \\
\mathrm{H}_{37} \mathrm{Rv}\end{array}$ & $\begin{array}{l}\mathrm{IC}_{50} \\
(\mu \mathrm{M})\end{array}$ & $\begin{array}{c}\mathrm{SI}^{b} \text { for } M . \\
\text { tuberculosis } \\
\mathrm{H}_{37} \mathrm{Rv}\end{array}$ \\
\hline $2 a$ & $\mathrm{Cl}$ & $4-\mathrm{CF}_{3}$ & 1.6 & 1.6 & 3.2 & $2.2 \pm 1.2$ & 1.4 & $5.8 \pm 1.9$ & 3.6 \\
\hline $2 b$ & $\mathrm{Cl}$ & 3,4-diCl & 1.6 & 1.6 & 3.2 & $3.8 \pm 0.5$ & 2.4 & $2.4 \pm 1.0$ & 1.5 \\
\hline $2 c$ & $\mathrm{Br}$ & $4-\mathrm{CF}_{3}$ & 1.4 & 2.8 & 13.9 & $2.0 \pm 0.4$ & 1.4 & $5.5 \pm 2.1$ & 3.9 \\
\hline $2 d$ & $\mathrm{Br}$ & 3,4-diCl & 1.4 & 2.8 & 7.0 & $1.4 \pm 0.5$ & 1.0 & $4.1 \pm 1.9$ & 2.9 \\
\hline
\end{tabular}

${ }^{a}$ Compound codes are identical as in Ref [9].

${ }^{b}$ Selectivity index, $\mathrm{SI}=\mathrm{IC}_{50}(\mu \mathrm{M}) / \mathrm{MIC}(\mu \mathrm{M})$

\subsection{In vitro cytostatic and cytotoxic activity}

Determination of the in vitro cytostatic effect of the compounds was carried out on human monocytic cell line MonoMac6 and on human hepatocellular carcinoma cell line HepG2 using MTT (3-(4,5dimethylthiazol-2-yl)-2,5-diphenyltetrazolium bromide) assay after $24 \mathrm{~h}$ of incubation. The $\mathrm{IC}_{50}$ values (the concentration which decreases the viability of the cells to $50 \%$ from the maximal viability) were determined from the dose-response curves and are presented in Table 3. The MonoMac6 cells are considered as an in vitro model of the host cell macrophages [52]. The HepG2 cells represent the model for the hepatotoxicity.

The cytotoxic activity of representative compounds was also determined on murine bone marrowderived macrophages (BMM $\Phi)$ using MTT assay after $48 \mathrm{~h}$ of incubation (Supporting Information Table S5). $\mathrm{BMM} \Phi$ cells can be considered also as macrophage model from normal primary cell culture that also expresses tuftsin receptors [53].

The selectivity indexes (SI) related to $M$. tuberculosis $\mathrm{H}_{37} \mathrm{Rv}$ strain were determined as a ratio of the $\mathrm{IC}_{50}$ value for cytostatic or cytotoxic activity to the MIC value (Table 2, Table 3 and Table S5).

Most of the acetylated control peptides have no cytostatic activity on MonoMac6 and HepG2 cells at the highest concentration measured $(200 \mu \mathrm{M})$ (Table 3). Interestingly, among the control peptides with fatty acid modification only the derivatives that contain palmitoyl group have cytostatic effect on both cell types. Ac-OT20(4-pal) showed the lowest $\mathrm{IC}_{50}$ value on MonoMac6 $(26.6 \mu \mathrm{M})$. Its isomer with palmitic acid on the ${ }^{14}$ Lys (Ac-OT20(14-pal)) has higher $\mathrm{IC}_{50}$ value $(62.8 \mu \mathrm{M})$ on MonoMac6. Inversely, the Ac-OT20(14-pal) has lower $\mathrm{IC}_{50}$ value $(35.2 \mu \mathrm{M})$ than Ac-OT20(4-pal) $(77.0 \mu \mathrm{M})$ on HepG2 cells. In the case of the shorter Ac-T5(4-pal) it has similar effect like Ac-OT20(14-pal) on both cells. The cytostatic effect of palmitic acid itself and the physical mixture of palmitic acid and Ac-OT20 control peptide was also studied on MonoMac6 cells, and the $\mathrm{IC}_{50}$ values are very similar (178.1 and $175.8 \mu \mathrm{M}$ respectively). The covalent bond between the palmitic acid and the peptide in the most cytostatic derivative Ac-OT20(4-pal) gives almost 7-times lower $\mathrm{IC}_{50}$ value than in the case of the palmitic acid alone. 
The previously published parent salicylanilides [9] have cytostatic activity at very low $\mathrm{IC}_{50}$ values between 1.4-5.8 $\mu \mathrm{M}$ on MonoMac6 and HepG2 cells (Table 2). All the three conjugable salicylanilide derivatives (SAL1-3) have cytostatic activity on both cells as well, but their $\mathrm{IC}_{50}$ values are higher than the $\mathrm{IC}_{50}$ values of the parent compounds (Table 3). The conjugable salicylanilides (SAL1-3) have very similar $\mathrm{IC}_{50}$ values between 16.1-21.5 $\mu \mathrm{M}$ on MonoMac6. SAL1 has the lowest value $(7.9 \mu \mathrm{M})$ for HepG2 cells, SAL2 and SAL3 has $\mathrm{IC}_{50}$ values of 15.9 and $17.6 \mu \mathrm{M}$, respectively.

In the case of the salicylanilide-tuftsin conjugates the results are diverse (Table 3). The conjugates with one tuftsin units (SAL2-Aoa-T5, SAL2-Aoa-T5-OH, SAL2-Aoa-TKPR-OH, SAL2-Aoa-TKPPR-OH) and their analogues elongated with GFLG spacer have no cytostatic activity on MonoMac6 cells at the highest measured concentration $(200 \mu \mathrm{M})$. Conjugates with two and four tuftsin units without a side chain modification (SAL2-Aoa-OT10, SAL1-Aoa-OT20, SAL2-Aoa-OT20, SAL3-Aoa-OT20) also does not show cytostatic effects on this cell. The OT20 conjugate elongated with the GFLG spacer (SAL2-Aoa-GFLGOT20) has a slight cytostatic activity on MonoMac6 $\left(\mathrm{IC}_{50}\right.$ of $\left.86.6 \mu \mathrm{M}\right)$. The presence of two salicylanilide molecules in the conjugate results in the appearance of cytostatic activity, namely SAL2-Aoa-OT20(4SAL2-Aoa) with $39.1 \mu \mathrm{M}$ and TKPR-OT10(8-SAL2-Aoa; 13-SAL2-Aoa) with $\mathrm{IC}_{50}$ of $101.4 \mu \mathrm{M}$ for MonoMac6 cells. The conjugates in which there are fatty acid side chain modification showed a significant cytostatic activity on MonoMac6 cells. The conjugate that have the shortest fatty acid side chain modification (with butanoyl side chain SAL2-Aoa-OT20(4-but)) has no cytostatic activity as an exception. All the palmitoyl side chain containing OT20 conjugates have very low and similar IC $_{50}$ values (16.5-20.9 $\mu \mathrm{M})$ and the T5 analogue (SAL2-Aoa-T5(4-pal)) has higher $\mathrm{IC}_{50}$ value $(53.8 \mu \mathrm{M})$. The two conjugates that have decanoyl side chain modification also have cytostatic activity. The SAL2-Aoa-OT20(4-dec) has IC 50 value of $24.9 \mu \mathrm{M}$ that is comparable with its analogue that have palmitoyl side chain modification (SAL2Aoa-OT20(4-pal), $16.8 \mu \mathrm{M})$. The T5 analogue SAL2-Aoa-T5(4-dec) has higher $\mathrm{IC}_{50}$ value $(72.6 \mu \mathrm{M})$ than SAL2-Aoa-T5(4-pal) $(53.8 \mu \mathrm{M})$. The finding that the decanoyl containing conjugates have cytostatic activity is in contrast that we experienced in the case of the control peptides (Ac-OT20(4-dec), Ac-T5(4-dec)) that did not show cytostatic activity nor the decanoic acid itself on MonoMac6 cells.

On HepG2 cells one OT20 conjugate (SAL2-Aoa-OT20) has a slight cytostatic activity $(81.9 \mu \mathrm{M})$, the others (SAL1-Aoa-OT20, SAL3-Aoa-OT20) and the OT10 derivative SAL2-Aoa-OT10 do not exhibited this action at the highest concentration measured. The conjugates with one tuftsin unit (SAL2-Aoa-T5, SAL2Aoa-TKPR-OH, SAL2-Aoa-TKPPR-OH) do not have cytostatic activity on HepG2 below $200 \mu \mathrm{M}$ except SAL2-Aoa-T5-OH which has a slight cytostatic effect with $\mathrm{IC}_{50}$ value of $191.3 \mu \mathrm{M}$. Interestingly, the presence of the GFLG spacer (SAL2-Aoa-GFLG-OT20, SAL2-Aoa-GFLG-T5, SAL2-Aoa-GFLG-T5-OH, SAL2-Aoa-GFLG-TKPR-OH, SAL2-Aoa-GFLG-TKPPR-OH) makes the conjugates slightly cytostatic on HepG2 cells ( $\mathrm{IC}_{50}$ values between 58.0-162.2 $\mu \mathrm{M}$ ). The conjugates containing two salicylanilide molecules have similar $\mathrm{IC}_{50}$ values to SAL2-Aoa-OT20, SAL2-Aoa-OT20(4-SAL2-Aoa) with $79.7 \mu \mathrm{M}$ and TKPROT10(8-SAL2-Aoa; 13-SAL2-Aoa) with $95.2 \mu \mathrm{M} \mathrm{IC}_{50}$ value. The conjugates with palmitic acid side chain modification showed a significant cytostatic activity on $\mathrm{HepG} 2$ cells too. The palmitoyl side chain containing OT20 conjugates have low and similar $\mathrm{IC}_{50}$ values (37.6-42.9 $\mu \mathrm{M}$ ). Interestingly, the T5 analogue (SAL2Aoa-T5(4-pal)) has the lowest $\mathrm{IC}_{50}$ value among all the conjugates $(23.2 \mu \mathrm{M})$. SAL2-Aoa-OT20 and its analogue with butanoyl side chain (SAL2-Aoa-OT20(4-but)) has the same effect (81.9 and $81.6 \mu \mathrm{M}$ respectively). On the contrary that we can observe in the case of cytostatic activity on MonoMac6 cells, on HepG2 cells the cytostatic activity of the OT20 conjugate that has decanoyl side chain modification (SAL2Aoa-OT20(4-dec)) is decreased $(113.3 \mu \mathrm{M})$. The T5 analogue SAL2-Aoa-T5(4-dec) has a higher cytostatic activity but its $\mathrm{IC}_{50}$ value $(55.8 \mu \mathrm{M})$ is still lower than the $\mathrm{IC}_{50}$ value of SAL2-Aoa-T5(4-pal) $(23.2 \mu \mathrm{M})$. 
Interestingly, the smallest metabolites from lysosomal degradation SAL2-Aoa-Thr-OH and SAL2Aoa-Gly-OH have no cytostatic activity on MonoMac6 cells nor on HepG2 cells at the highest measured concentration $(200 \mu \mathrm{M})$. The presence of the oxime bonded amino acid derivative on the salicylanilide abolishes the cytostatic activity. The disappearance of the cytostatic activity is presumably because the conjugates and the smallest fragments are not getting into the same cell compartment.

In the case of the parent salicylanilide derivatives selectivity indexes calculated to M. tuberculosis $\mathrm{H}_{37} \mathrm{Rv}$ ranged from 1.0 to 2.4 for MonoMac6 cells and from 1.5 to 3.9 for HepG2 cells. The conjugable derivatives have similar SI values for both cell lines, 0.8-2.5 for MonoMac6 cells and 0.7-2.1 for HepG2 cells.

However, most of the conjugates were not cytostatic or possessed low cytostatic activity, their selectivity towards $M$. tuberculosis $\mathrm{H}_{37} \mathrm{Rv}$ starts at low selectivity indexes due to their higher MIC values. The conjugates with decanoic acid or palmitic acid side chain modification have SI values between 0.1 and 1.5. SAL2-Aoa-OT20(4-SAL2-Aoa) conjugate with two drug molecules has SI value below 1.9 for both cells, however, TKPR-OT10(8-SAL2-Aoa; 13-SAL2-Aoa) with also two drug molecules has slightly better SI value, 2.9 and 2.7 for MonoMac6 and HepG2 respectively. The conjugates (SAL1-Aoa-OT20, SAL3Aoa-OT20, SAL2-Aoa-T5, SAL2-Aoa-T5-OH, SAL2-Aoa-TKPR-OH, SAL2-Aoa-TKPPR-OH) that have no cytostatic activity on MonoMac6 or HepG2 cells at the highest measured concentration $(200 \mu \mathrm{M})$ exhibited the most favourable selectivity towards bacteria, their SI values are above 2.4 or even above 9 for MonoMac6 and HepG2 cells with SAL2-Aoa-TKPPR-OH superiority. In these cases, we can conclude that the conjugation of salicylanilide derivatives to tuftsin type carriers improved their selectivity toward the bacteria.

On BMM $\Phi$ cells (murine bone marrow-derived macrophages) the salicylanilide derivative SAL2 itself has a moderate cytotoxic effect $(76.5 \mu \mathrm{M})$ resulted in high selectivity index (10.2) towards bacteria (Table S5). Its conjugates with the monotuftsin derivative (SAL2-Aoa-T5) and with the tetratuftsin derivative (SAL2-Aoa-OT20) have no cytotoxicity at the highest measured concentration $(100 \mu \mathrm{M})$. Their selectivity indexes are above 4.6 and 1.2, respectively. The incorporation of the GLFG spacer resulted in a low cytotoxic activity in the case of SAL2-Aoa-GFLG-OT20 with $\mathrm{IC}_{50}$ value of $92.1 \mu \mathrm{M}$. The fatty acid side chain modification also increased the cytotoxicity, SAL2-Aoa-OT20(4-dec) has a moderate cytotoxic activity $\left(\mathrm{IC}_{50}\right.$ of $\left.71.9 \mu \mathrm{M}\right)$ and SAL2-Aoa-OT20(4-pal) has a high cytotoxic activity $\left(\mathrm{IC}_{50}\right.$ of $\left.20.4 \mu \mathrm{M}\right)$ on $\mathrm{BMM} \Phi$ cells. Therefore, their selectivity indexes are not favourable, SI is below 1 . 
Table 3. Cytostatic activity ( $24 \mathrm{~h})$ on MonoMac6 and HepG2 cells of SAL1-3, the salicylanilide-tuftsin conjugates, the control peptides and selectivity indexes calculated for M. tuberculosis $\mathrm{H}_{37} \mathrm{Rv}$

\begin{tabular}{|c|c|c|c|c|}
\hline \multirow[b]{2}{*}{ compound, conjugate code $\mathrm{e}^{a}$} & \multicolumn{2}{|c|}{ MonoMac6 } & \multicolumn{2}{|c|}{ HepG2 } \\
\hline & $\mathrm{IC}_{50}(\mu \mathrm{M})$ & $\begin{array}{c}\mathrm{SI}^{b} \text { for } M . \\
\text { tuberculosis } \mathrm{H}_{37} \mathrm{Rv}\end{array}$ & $\mathrm{IC}_{50}(\mu \mathrm{M})$ & $\begin{array}{c}\text { SI }^{b} \text { for } M . \\
\text { tuberculosis } \mathrm{H}_{37} \mathrm{Rv}\end{array}$ \\
\hline SAL1 & $16.1 \pm 4.9$ & 1.9 & $7.9 \pm 1.4$ & 0.9 \\
\hline SAL2 & $18.6 \pm 2.5$ & 2.5 & $15.9 \pm 0.0$ & 2.1 \\
\hline SAL3 & $21.5 \pm 7.1$ & 0.8 & $17.6 \pm 1.6$ & 0.7 \\
\hline SAL1-Aoa-OT20 & $>200$ & $>2.4$ & $>200$ & $>2.4$ \\
\hline SAL2-Aoa-OT20 & $>200$ & $>2.5$ & $81.9 \pm 4.2$ & 1.0 \\
\hline SAL3-Aoa-OT20 & $>200$ & $>2.4$ & $>200$ & $>2.4$ \\
\hline SAL2-Aoa-GFLG-OT20 & $86.6 \pm 2.8$ & 0.6 & $112.4 \pm 20.0$ & 0.8 \\
\hline SAL2-Aoa-OT20(4-but) & $>200$ & $>3.2$ & $81.6 \pm 2.4$ & 1.3 \\
\hline SAL2-Aoa-OT20(4-dec) & $24.9 \pm 6.2$ & 0.3 & $113.3 \pm 15.3$ & 1.5 \\
\hline SAL1-Aoa-OT20(4-pal) & $16.8 \pm 3.1$ & 0.2 & $42.9 \pm 8.9$ & 0.5 \\
\hline SAL2-Aoa-OT20(4-pal) & $16.5 \pm 0.8$ & 0.2 & $37.6 \pm 10.3$ & 0.4 \\
\hline SAL2-Aoa-OT20(14-pal) & $20.9 \pm 4.0$ & 0.3 & $40.4 \pm 17.7$ & 0.5 \\
\hline SAL2-Aoa-OT20(4-SAL2-Aoa) & $39.1 \pm 1.6$ & 0.9 & $79.7 \pm 16.7$ & 1.9 \\
\hline SAL2-Aoa-OT10 & $>200$ & $>1.1$ & $>200$ & $>1.1$ \\
\hline TKPR-OT10(8-SAL2-Aoa; 13-SAL2-Aoa) & $101.4 \pm 5.6$ & 2.9 & $95.2 \pm 4.2$ & 2.7 \\
\hline SAL2-Aoa-T5 & $>200$ & $>9.2$ & $>200$ & $>9.2$ \\
\hline SAL2-Aoa-GFLG-T5 & $>200$ & $>6.5$ & $162.6 \pm 17.3$ & 5.3 \\
\hline SAL2-Aoa-T5(4-dec) & $72.6 \pm 6.7$ & 0.4 & $55.8 \pm 3.0$ & 0.3 \\
\hline SAL2-Aoa-T5(4-pal) & $53.8 \pm 1.1$ & 0.3 & $23.2 \pm 3.7$ & 0.1 \\
\hline SAL2-Aoa-T5-OH & $>200$ & $>3.1$ & $191.3 \pm 12.4$ & 2.9 \\
\hline SAL2-Aoa-GFLG-T5-OH & $>200$ & $>4.3$ & $58.0 \pm 0.1$ & 1.3 \\
\hline SAL2-Aoa-TKPR-OH & $>200$ & $>4.4$ & $>200$ & $>4.4$ \\
\hline SAL2-Aoa-GFLG-TKPR-OH & $>200$ & $>6.3$ & $112.6 \pm 26.9$ & 3.6 \\
\hline SAL2-Aoa-TKPPR-OH & $>200$ & $>9.9$ & $>200$ & $>9.9$ \\
\hline SAL2-Aoa-GFLG-TKPPR-OH & $>200$ & $>6.8$ & $155.6 \pm 14.8$ & 5.3 \\
\hline SAL2-Aoa-Thr-OH & $>200$ & $>0.5$ & $>200$ & $>0.5$ \\
\hline SAL2-Aoa-Gly-OH & $>200$ & $>0.9$ & $>200$ & $>0.9$ \\
\hline most of the acetylated control peptides & $>200$ & - & $>200$ & - \\
\hline Ac-OT20(4-pal) & $26.6 \pm 2.2$ & - & $77.0 \pm 7.1$ & - \\
\hline Ac-OT20(14-pal) & $62.8 \pm 4.5$ & - & $35.2 \pm 5.2$ & - \\
\hline Ac-T5(4-pal) & $64.0 \pm 0.6$ & - & $43.5 \pm 7.9$ & - \\
\hline decanoic acid & $>200$ & - & $\mathrm{nd}^{c}$ & - \\
\hline palmitic acid & $178.1 \pm 11.2$ & - & nd & - \\
\hline palmitic acid + SAL2-Aoa-OT20 physical mixture & $169.0 \pm 1.7$ & - & nd & - \\
\hline palmitic acid + Ac-OT20 physical mixture & $175.8 \pm 14.0$ & - & nd & - \\
\hline
\end{tabular}

${ }^{a}$ The C-terminal of the peptides is in amide form if it is not indicated otherwise, the peptides with carboxylic C-terminal is always indicated with -OH.

${ }^{b}$ Selectivity index, $\mathrm{SI}=\mathrm{IC}_{50}(\mu \mathrm{M}) / \mathrm{MIC}(\mu \mathrm{M})$

${ }^{c}$ nd: not determined. 


\subsection{Study of the pH dependence of the fluorescence intensity of the fluorescently labelled tuftsin derivatives}

It is important to know the fluorescent properties of the fluorescently labelled different tuftsin derivatives to be able to compare their cellular uptake rates. Therefore prior to the cellular uptake studies the $\mathrm{pH}$ dependence of the fluorescence intensity of the fluorescently labelled tuftsin derivatives was studied in citric acid $-\mathrm{Na}_{2} \mathrm{HPO}_{4}$ buffers at 8 and $50 \mu \mathrm{M}$ concentration using Varian Cary Eclipse Fluorescence Spectrophotometer. Preparation of buffers can be found in Supporting Information Table S6. As excitation wavelength $488 \mathrm{~nm}$ was used and the emission was measured between 490 and $700 \mathrm{~nm}, 450 \mathrm{~V}$ detector voltage was used. At the different concentrations similar tendency in the fluorescence intensity was observed, data obtained at $50 \mu \mathrm{M}$ are presented here, data obtained at $8 \mu \mathrm{M}$ are presented in Supporting Information (Figure S8-S9).

The fluorescence intensity and the emission maximum wavelength of all 5(6)-carboxyfluorescein labelled peptides (Cf-tuftsin derivatives) and the free 5(6)-carboxyfluorescein increase along with $\mathrm{pH}$ between $\mathrm{pH} 4$ and $\mathrm{pH}$ 6. Between $\mathrm{pH} 6$ and $\mathrm{pH} 7.6$ no significant differences in the intensity and emission maximum wavelength was observed, at these $\mathrm{pH}$ values the fluorescence intensity and the emission maximum wavelength is the highest. Most of the peptides and the free 5(6)-carboxyfluorescein follow the same emission spectra profile. The emission spectra at different $\mathrm{pH}$ values of Cf-OT20 and Cf-T5 are showed as an example in Figure 2A and B. The emission spectra of all Cf-tuftsins at $\mathrm{pH} 7$ are compared in Figure 2C. The sequence, the number of tuftsin units, the presence of the spacer, the presence of butyric or decanoic acid has no significant effect on the fluorescent properties of the peptides. However, in the case of peptides with palmitic acid at the $4^{\text {th }}$ position (Cf-OT20(4-pal) and Cf-T5(4-pal)) the fluorescence intensity dramatically decreased at all $\mathrm{pH}$ value. At this distance the palmitic acid can have quenching effect to the fluorophore. When the palmitic acid is in the $14^{\text {th }}$ position (Cf-OT20(14-pal)) no decrease in the intensity was observed. In the case of the salicylanilide containing fluorescent conjugate SAL2-Aoa-OT20(4-Cf) decrease in the florescence intensity also was observed, the salicylanilide also can have quenching effect at this distance. 
A

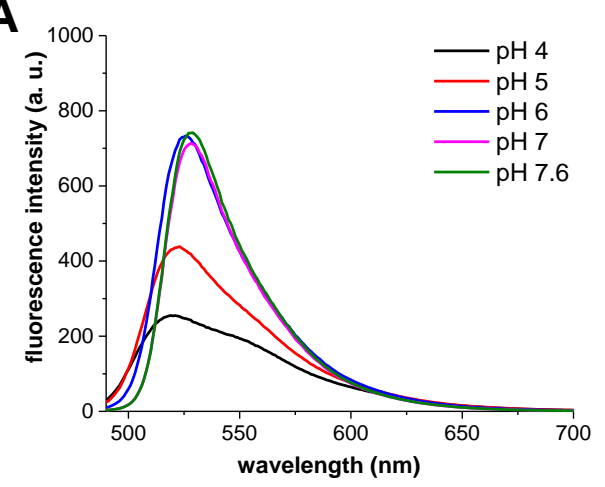

B

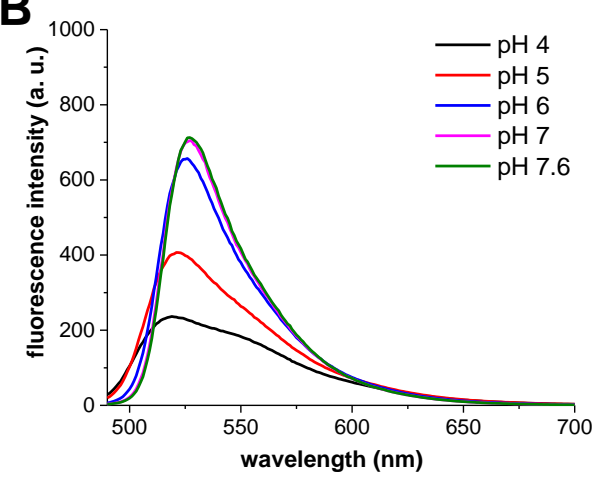

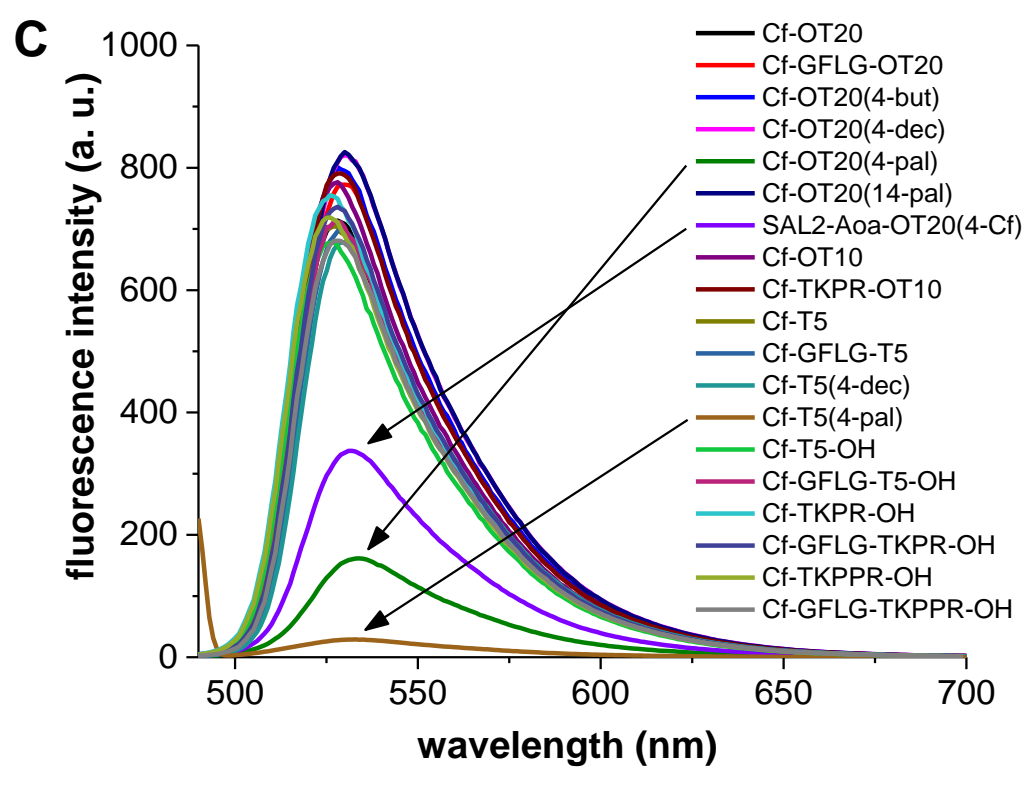

Figure 2. Comparison of the $\mathrm{pH}$ dependence of the fluorescence intensity of the Cf-labelled tuftsin derivatives: (A) Cf-OT20 and (B) Cf-T5. (C) Comparison of the fluorescence intensity of the different Cflabelled tuftsin derivatives at $\mathrm{pH} 7$ at $50 \mu \mathrm{M}$, in $0.1 \mathrm{M}$ citric acid - $0.2 \mathrm{M} \mathrm{Na}_{2} \mathrm{HPO}_{4}$ buffer. The arrows indicate the compounds with lower fluorescence intensity than the average.

\subsection{Cellular uptake experiments of fluorescently labelled tuftsin derivatives}

The in vitro cellular uptake of the different fluorescently labelled tuftsin derivatives was evaluated on MonoMac6 human monocytic cell culture using flow cytometry (BD LSRII) and fluorescent microscopy (Olympus CKX41). The cells were treated with the compounds for $3 \mathrm{~h}$, after washing and trypsinization, the cells were transferred into tubes and their intracellular fluorescence intensity was measured that is related with the cellular uptake rate.

The uptake of all tuftsin derivatives is concentration dependent in MonoMac6 cells. The concentration dependency of the uptake of representative Cf-labelled tuftsin derivatives is presented in Supporting Information Figure S10. In Figure 3A the mean intracellular fluorescence intensity of the living Cf positive cells treated with the compounds at the highest measured concentration $(200 \mu \mathrm{M})$ is compared. The uptake depends on the number of the tuftsin unites: the internalization of the longer peptides is higher than internalization of the shorter ones (Cf-OT20 > Cf-OT10 > Cf-T5). The uptake of the peptides with one tuftsin unite (Cf-T5, Cf-T5-OH, Cf-TKPR-OH and Cf-TKPPR-OH) is very similar, the form of the Cterminal does not have significant effect (amide or free carboxyl form, Cf-T5 vs. Cf-T5-OH). The presence 
of the GFLG spacer slightly reduced the internalization. The small differences in the lipophilicity of the peptides seem to have no effect on the uptake.

The OT20 derivatives with palmitic acid side chain (Cf-OT20(4-pal) and Cf-OT20(14-pal)) showed an extremely high uptake rate. At the applied experimental condition they have approximately 36-times higher uptake rate than their analogue without palmitic acid (Cf-OT20). The position of the palmitic acid in the sequence has no influence on the intracellular fluorescence intensity. The smaller peptide with palmitic acid (Cf-T5(4-pal)) has approximately four-times smaller uptake rate than the longer ones (Cf-OT20(4-pal) and Cf-OT20(14-pal)) but this rate is still more higher than the peptides without palmitic acid. Cf-T5(4-pal) has 20-times higher uptake rate than Cf-T5 without fatty acid. Unfortunately, these compounds showed a cytotoxic activity after $3 \mathrm{~h}$ treatment at this concentration of $200 \mu \mathrm{M}$. Table 4 shows the $3 \mathrm{~h} \mathrm{IC}_{50}$ values of the Cf-peptides calculated from the percentage of the living cells determined by the flow cytometer according to the size and granularity of the cells. In the case of the peptides with decanoic acid side chain modification the longer Cf-OT20(4-dec) has a significantly higher internalization rate among the peptides; it has 8-times higher uptake rate than Cf-OT20 and almost 10-times higher uptake rate than the smaller CfT5(4-dec). It should also be noted that Cf-T5(4-dec) has two-times higher uptake rate than its analogue without decanoic acid (Cf-T5). The uptake rate of Cf-OT20(4-pal) is almost 5-times higher than its analogue with decanoic acid (Cf-OT20(4-dec)). The advantage of using decanoic acid modification instead of palmitic acid is that the derivatives with decanoic acid have no cytotoxic activity after $3 \mathrm{~h}$ treatment. Introduction of butyric acid side chain has no significant effect (Cf-OT20 vs. Cf-OT20(4-but)). The increasing cellular uptake of peptides with decanoic or palmitic acid side chain can be the result of their higher lipophilic characters (according to retention time data from TableS1) than their analogues without these fatty acid side chains.

Interestingly, the fluorescently labelled OT20 derivative that has salicylanilide moiety conjugated to it (SAL2-Aoa-OT20(4-Cf)) has almost two-times higher uptake rate than the Cf-OT20 without salicylanilide moiety. Again this finding can be explained by the increased lipophilicity in the case of SAL2-Aoa-OT20(4Cf).

Figure 3B shows the mean fluorescence intensity values of the living cells treated with $8 \mu \mathrm{M}$ and 40 $\mu \mathrm{M}$ solutions of the selected peptides. The palmitic acid containing peptides does not have cytotoxic activity at the concentration of $8 \mu \mathrm{M}$, the rate of the living cells is above $80 \%$, in the case of the untreated control cells this is $95 \%$. At this concentration the intracellular fluorescence intensity of the cells treated with derivatives with decanoic acid (Cf-OT20(4-dec) and Cf-T5(4-dec)) and their analogue without fatty acid side chain (Cf-OT20 and Cf-T5) is only slightly higher than the fluorescence of the untreated control cells. However, the uptake rate of the derivatives with palmitic acid side chain modification (Cf-OT20(4-pal), CfOT20(14-pal), Cf-T5(4-pal)) is still very significant at the concentration of $8 \mu \mathrm{M}$.

The cellular uptake of selected fluorescently labelled tuftsin derivatives was visualized using fluorescent microscopy (Figure 4). The morphology of the cells treated with most of the Cf-peptides is normal, similar to control cells. The morphology of the cells treated with Cf-peptides that contain palmitic acid side chain moiety is different when the cells were treated with $200 \mu \mathrm{M}$ and $40 \mu \mathrm{M}$ of the peptide, at 8 $\mu \mathrm{M}$ the cell morphology remains normal. Figure 4F-H shows the microscopic images of the MonoMac6 cells treated with Cf-OT20(4-pal) at different concentrations as an example.

The comparison of the mean intracellular fluorescence intensity values of the cells treated with the different peptides is adequate in the case of most of the peptides that have similar fluorescent properties. In the case of Cf-OT20(4-pal), Cf-T5(4-pal) and SAL2-Aoa-OT20(4-Cf), where the peptides have lower fluorescent intensity under the same circumstances probably because of self-quenching, higher cellular 
uptake rate was measured than in the case of the other peptides. This fact implies that the peptide is degraded in the cells and the self-quenching is eliminated. The position of the palmitic acid in the peptide sequence has no influence to the cellular uptake rate, no significant difference between the intracellular fluorescence intensity was observed in the case of Cf-OT20(4-pal) and Cf-OT20(14-pal). However, in buffers at the measured $\mathrm{pH}$ values the fluorescence intensity of Cf-OT20(14-pal) is much higher than the fluorescence intensity of Cf-OT20(4-pal). This finding suggests that the Cf-OT20(4-pal) and the Cf-OT20(14-pal) must be degraded in the cell therefore the self-quenching is abolished resulting the same intracellular fluorescence intensity.
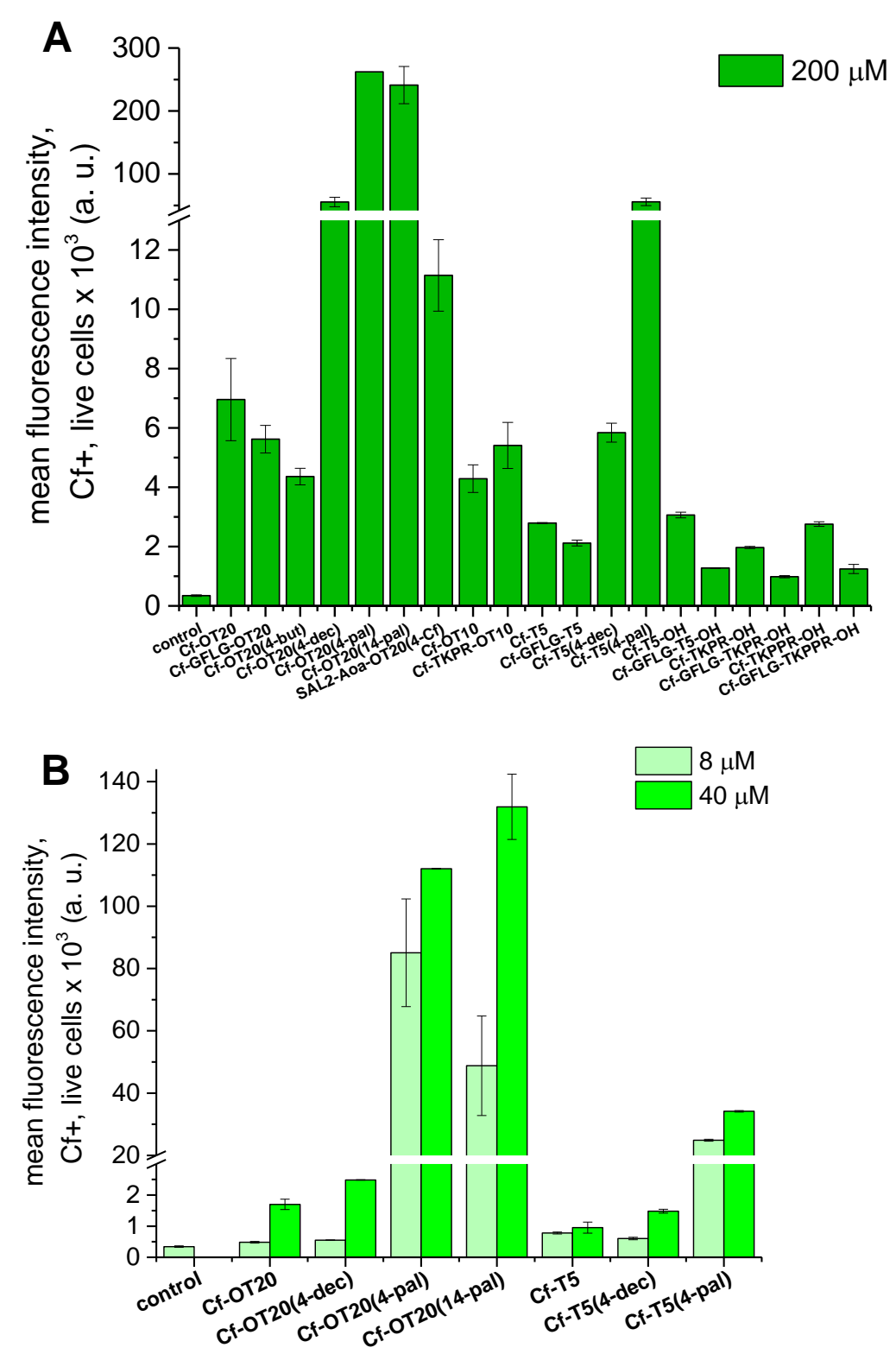

Figure 3. (A) Comparison of the cellular uptake on MonMac6 cells of the different fluorescently labelled tuftsin derivatives using flow cytometry at $200 \mu \mathrm{M}$ compound concentration ( $3 \mathrm{~h}$ incubation time). (B) Comparison of the cellular uptake of selected fluorescently labelled tuftsin derivatives at $8 \mu \mathrm{M}$ and $40 \mu \mathrm{M}$ compound concentrations ( $3 \mathrm{~h}$ incubation time). 
Table 4. Cytotoxic activity ( $3 \mathrm{~h}$ ) of the fluorescently labelled peptides on MonoMac6 cells determined by the data from the measurement with flow cytometer

\begin{tabular}{lc}
\hline \multicolumn{1}{c}{ compound, conjugate code } \\
\end{tabular}

${ }^{a}$ The C-terminal of the palmitoylated peptides is in amide form.
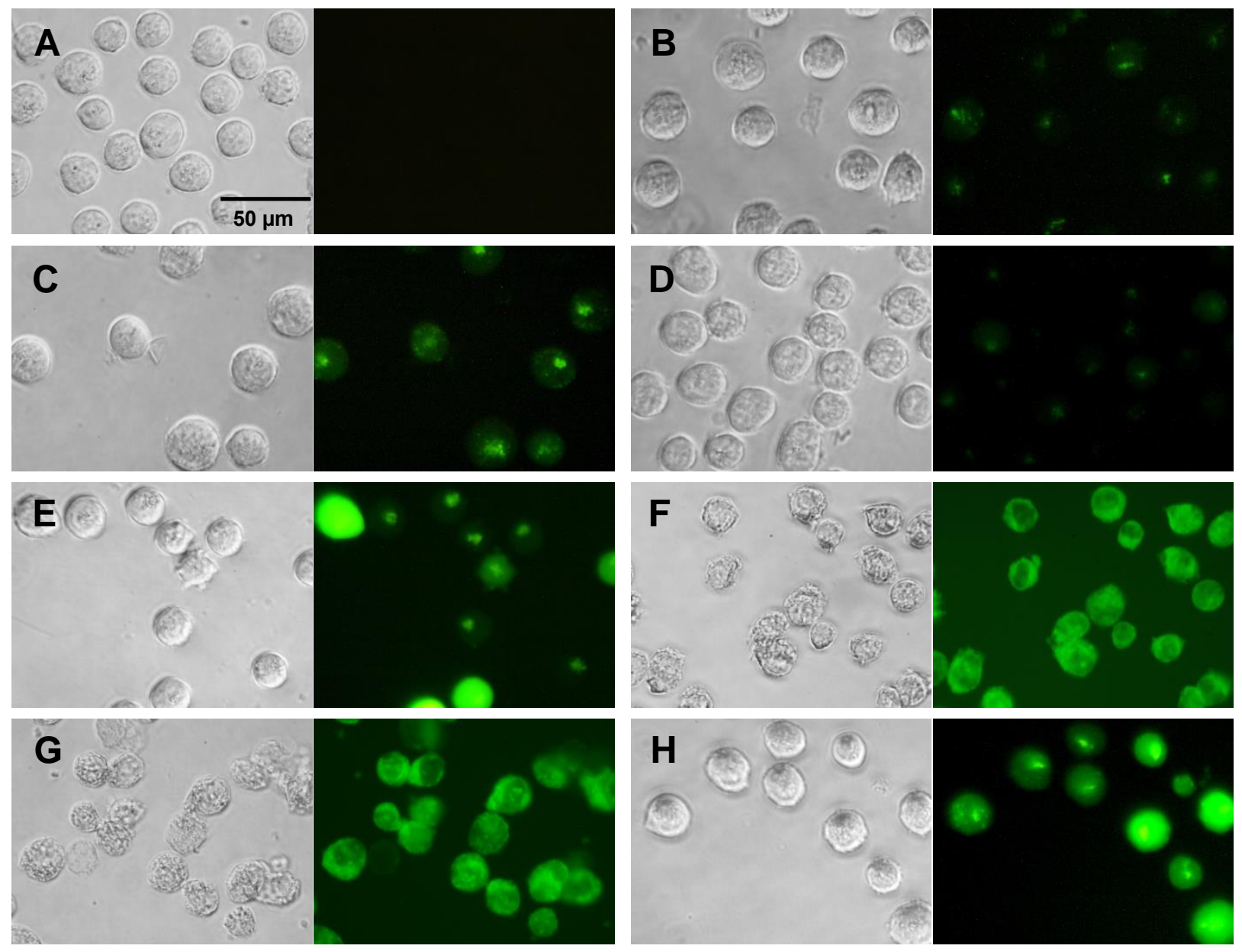

Figure 4. Comparison of the cellular uptake $(3 \mathrm{~h})$ of selected fluorescently labelled tuftsin derivatives on MonoMac6 cells using fluorescent microscopy, bright field microscopic images and fluorescent microscopic images are shown. (A) Untreated control cells, (B) Cf-OT20, $200 \mu \mathrm{M}$, (C) SAL2-Aoa-OT20(4-Cf), $200 \mu \mathrm{M}$, (D) Cf-T5, $200 \mu \mathrm{M}$, (E) Cf-OT20(4-dec), $200 \mu \mathrm{M}$, (F) Cf-OT20(4-pal), $200 \mu \mathrm{M}$, (G) Cf-OT20(4-pal), 40 $\mu \mathrm{M}$, (H) Cf-OT20(4-pal), $8 \mu \mathrm{M}$.

The cellular uptake of the selected fluorescently labelled tuftsin derivatives (Cf-OT20, Cf-GFLGOT20, Cf-OT20(4-dec), Cf-OT20(4-pal), Cf-OT10, Cf-T5, Cf-TKPR-OH, Cf-TKPPR-OH) was also evaluated on murine bone marrow-derived macrophages (BMM $\Phi$, macrophage model from normal primary cell culture with tuftsin receptors [53]) using flow cytometry and fluorescent microscopy. The cells were 
treated with the compounds for $3 \mathrm{~h}$, after washing and trypsinization, the cells were transferred into tubes and their intracellular fluorescence intensity was measured.

The uptake of the selected Cf-tuftsin derivatives by MonoMac6 cells (Supporting Information Figure S11). The uptake rate of the longer peptides is higher than the shorter peptides, but with slighter difference (Cf-OT20>Cf-OT10>Cf-T5). No significant difference can be observed between the intracellular fluorescence intensity of Cf-OT20 and its analogue elongated with the GFLG spacer, Cf-GFLG-OT20. The uptake rate of the small Cf-TKPR-OH and Cf-TKPPR-OH is higher than the rate of the Cf-T5, their intracellular fluorescent intensity is similar to the intensity of Cf-OT20 tetratuftsin derivative. The uptake rate of Cf-OT20(4-dec) and Cf-OT20(4-pal) decanoylated and palmitoylated tetratuftsin derivatives are outstanding, similarly as in the case of the MonoMac6 cells.

\subsection{Membrane integrity studies by propidium iodide staining}

Propidium iodide (PI) is used to distinguish the dead or nonviable cells from living cells, as PI only stains cells with irreparably damaged membranes that can be described as nonviable or dead [54]. Therefore, PI staining was used to compare the effect of the control acetylated tuftsin derivatives with or without fatty acid side chains (Ac-OT20, Ac-OT20(4-dec), Ac-OT20(4-pal) and Ac-OT20(14-pal)) to the cell membrane integrity using flow cytometry and fluorescent microscopy. MonoMac6 cells were treated with the peptide derivatives for $3 \mathrm{~h}$, at different concentrations $(8,40$ and $200 \mu \mathrm{M})$, after washing and trypsinization, the cells were transferred into tubes and solution of PI was added to it. The intracellular fluorescence intensity was measured before and after adding the PI solution.

In Figure 5 the microscopic image shows the MonoMac6 cells with PI after treatment with the compounds for $3 \mathrm{~h}$ at $200 \mu \mathrm{M}$. The Ac-OT20 with no fatty acid side chain and the Ac-OT20(4-dec) with decanoyl side chain have no influence on the membrane integrity. The presence of PI can be observed only in the cells that were treated with palmitoylated tuftsin derivatives (Ac-OT20(4-pal) and Ac-OT20(14-pal)), these cells have altered cell morphology and presumably changed cell viability. These palmitoylated peptides have the same effect at $40 \mu \mathrm{M}$ concentration (data not shown), but at $8 \mu \mathrm{M}$ the rate of the membrane damaged cells is decreased. The percentage of the nonviable cells and the percentage of the nonviable and PI containing cells are shown in Supporting Information Figure S12. These results are consistent with the microscopic images. 

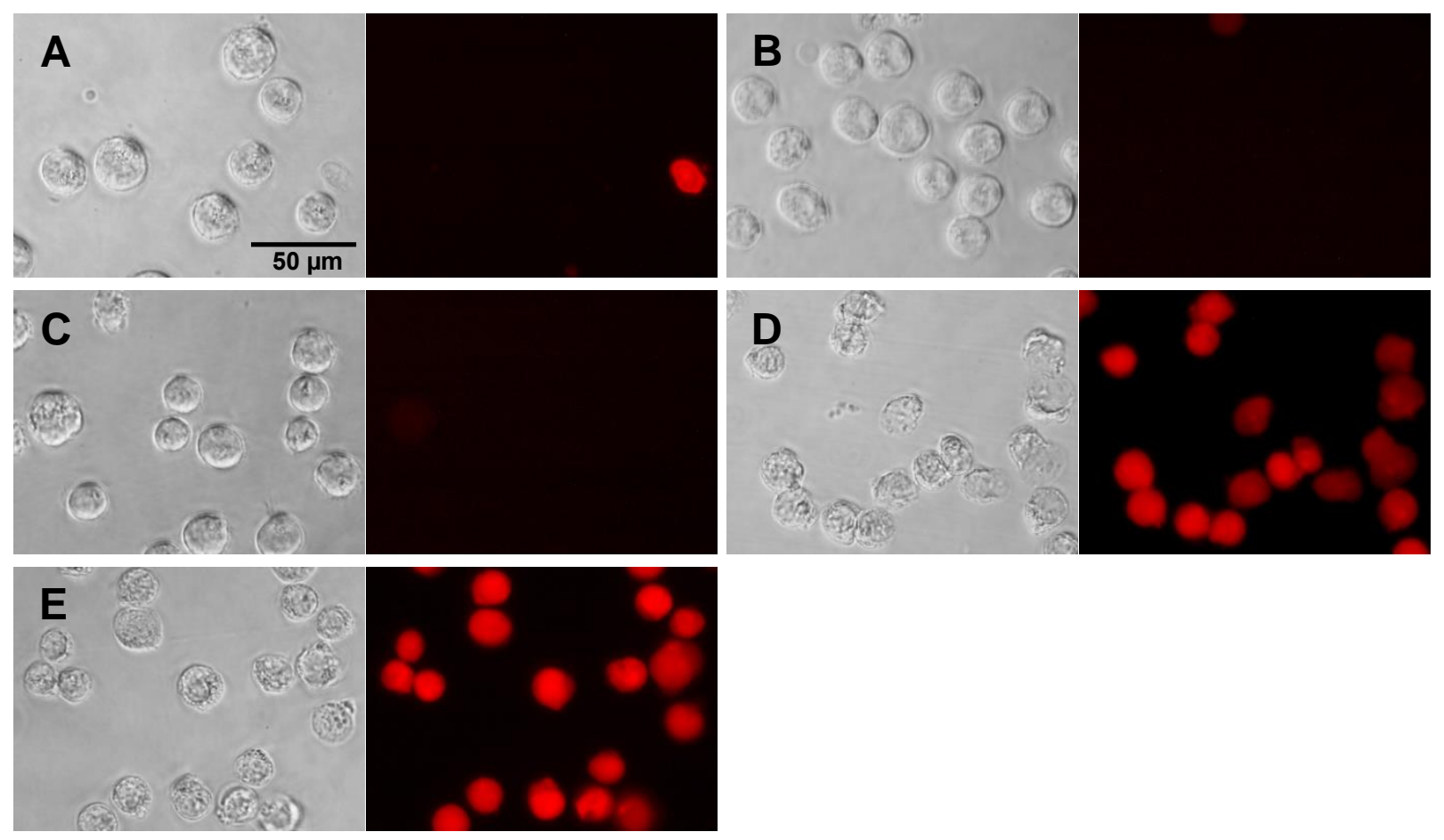

Figure 5. Membrane integrity studies with propidium iodide (PI) staining of MonoMac6 cells after treatment $(3 \mathrm{~h}, 200 \mu \mathrm{M})$ with acetylated tuftsin derivatives with different fatty acid side chain modification using fluorescent microscopy, bright field microscopic images and fluorescent microscopic images are shown. (A) Untreated control cells, (B) Ac-OT20, (C) Ac-OT20(4-dec), (D) Ac-OT20(4-pal), (E) Ac-OT20(14-pal).

\subsection{Degradation study of SAL2-tuftsin conjugates in rat liver lysosomal homogenate}

The efficacy of the conjugates is related to their degradation and the intracellular drug release from the conjugates in the target cells therefore we studied the stability/degradation of the conjugates in rat liver lysosomal homogenate by liquid chromatography in combination with mass spectrometry (HPLC-MS). Lysosomes, intracellular organelles that have an internal acidic $\mathrm{pH}(\mathrm{pH}$ 4.5-5.0) [55] and contain a wide variety of hydrolytic enzymes, play a crucial role in the intracellular drug release.

Analyses (LC-MS chromatogram, mass spectra) of the reaction mixtures of SAL2-Aoa-OT20, SAL2Aoa-GFLG-OT20, SAL2-Aoa-OT20(4-dec), SAL2-Aoa-OT20(4-pal), SAL2-Aoa-OT20(14-pal), SAL2Aoa-OT20(4-SAL2-Aoa), SAL2-Aoa-OT10, SAL2-Aoa-T5, SAL2-Aoa-GFLG-T5, SAL2-Aoa-T5(4-dec), SAL2-Aoa-T5(4-pal), SAL2-Aoa-T5-OH, SAL2-Aoa-TKPR-OH, SAL2-Aoa-TKPPR-OH after 5 min, 1 h, 2 $\mathrm{h}, 4 \mathrm{~h}, 8 \mathrm{~h}$ and $24 \mathrm{~h}$ are presented in the Supporting Information Figure S13-S27. The smallest drug containing metabolite was the SAL2-Aoa-Thr-OH from conjugates without spacer and SAL2-Aoa-Gly-OH from conjugates with spacer. SAL2-Aoa-OT20(4-SAL2-Aoa) conjugate released SAL2-Aoa-Thr-OH and HLys(SAL2-Aoa)-OH according to its structure. No cleavage of the oxime bond and no free salicylanilide was observed. Figure 6 summarizes the detected cleavage sites during the digestion of the conjugates.

In the case of most of the TKPKG derivatives without spacer (SAL2-Aoa-OT20, SAL2-Aoa-OT20(4dec), SAL2-Aoa-OT20(4-pal), SAL2-Aoa-OT20(14-pal), SAL2-Aoa-OT20(4-SAL2-Aoa), SAL2-AoaOT10, SAL2-Aoa-T5, SAL2-Aoa-T5(4-dec), SAL2-Aoa-T5-OH) the first cleavage sites were observed after 5 min next to the Gly residues (-Lys-Gly- bond and -Gly-Thr- bond). After $1 \mathrm{~h}$ the degradation continued, in the case of the OT20 derivatives only a small amount of the intact conjugate was observed, and after $2 \mathrm{~h}$ there were no intact conjugate in the samples with the exception of the SAL2-Aoa-OT20(4-pal) conjugate. The degradation of SAL2-Aoa-OT20(4-pal) was slow, several cleavage sites were observed. The intact 
SAL2-Aoa-OT20(4-pal) was detected in a very small amount even after $24 \mathrm{~h}$ of incubation. The palmitic acid in the position 4 slows down the degradation of the conjugate, however, the palmitic acid in the position 14 has no significant influence on the degradation rate. In the case of the two drug molecule containing conjugate SAL2-Aoa-OT20(4-SAL2-Aoa) the H-Lys(SAL2-Aoa)-OH fragment was released sooner with the cleavage of $-{ }^{3}$ Pro- ${ }^{4}$ Lys(SAL2-Aoa)- and ${ }_{-}^{4}$ Lys(SAL2-Aoa)- ${ }^{5}$ Gly- bonds than the SAL2-Aoa-Thr-OH fragment from the $\mathrm{N}$-terminal of the conjugate.

The degradation of SAL2-Aoa-OT10 is slower than the degradation of SAL2-Aoa-OT20, intact SAL2-Aoa-OT10 conjugate is present after $24 \mathrm{~h}$ and the SAL2-Aoa-T5-OH fragment is the most intensive after $24 \mathrm{~h}$. In the case of the SAL2-Aoa-T5 and SAL2-Aoa-T5-OH the degradation pattern is the same with a very slow degradation rate, after $24 \mathrm{~h}$ the most intensive component is the intact conjugate in both case. The degradation rate of SAL2-Aoa-T5(4-pal) is very low, similar to its analogue without the palmitic acid side chain modification (SAL2-Aoa-T5). The presence of the decanoic acid caused the most noticeable difference in the digestion of the T5 derivatives. Contrary to the SAL2-Aoa-T5 and SAL2-Aoa-T5(4-pal), the SAL2Aoa-T5(4-dec) conjugate was completely degraded after $2 \mathrm{~h}$. In the case of SAL2-Aoa-OT20(4-dec) and SAL2-Aoa-T5(4-dec) cleavage of $-{ }^{3}$ Pro- ${ }^{4} \mathrm{Lys}(\mathrm{dec})$ - bond occurred already after $5 \mathrm{~min}$. The decanoic acid containing conjugates are digested faster than the other analogues, so the presence of decanoic acid speeds up the degradation process. Palmitic acid loss (hydrolysis of the amide bond between the $\varepsilon$-amino group of Lys and carboxyl group of palmitic acid) occurred in all the palmitic acid containing conjugates, however, decanoic acid loss was not observed. In the case of SAL2-Aoa-TKPR-OH conjugate after 5 min the first cleavage sites appeared between $-{ }^{3}$ Pro- ${ }^{4}$ Arg- and $-{ }^{2}$ Lys- ${ }^{3}$ Pro- bond. After $24 \mathrm{~h}$ a small amount of the intact conjugate was still present, the main fragments were SAL2-Aoa-TK-OH and SAL2-Aoa-Thr-OH. In the case of its analogue with an extra proline SAL2-Aoa-TKPPR-OH conjugate, the first cleavage site after 5 min is the cleavage of the $-^{4}$ Pro- ${ }^{5}$ Arg- bond. The resulting SAL2-Aoa-TKPP-OH showed a high stability towards the lysosomal enzymes, this is the main fragment after $24 \mathrm{~h}$, and only a small part of this fragment could be degraded further to smaller metabolites. According to the analysis of the GFLG spacer containing conjugates the spacer sequence was primarily hydrolysed in the presence of lysosomal enzymes, the cleavage of - ${ }^{1}$ Gly${ }^{2} \mathrm{Phe}-,{ }_{-}^{2} \mathrm{Phe}-{ }_{-}^{3} \mathrm{Leu}-$ and $-{ }_{-}^{3} \mathrm{Leu}-{ }_{-}^{4} \mathrm{Gly}$ - bond was detected after $5 \mathrm{~min}$. There is no intact conjugate after $2 \mathrm{~h}$, small amount of SAL2-Aoa-GF-OH is observed between $5 \mathrm{~min}$ and $8 \mathrm{~h}$, but after $24 \mathrm{~h}$ only the smallest fragment, SAL2-Aoa-Gly-OH is detected. The insertion of enzyme labile GFLG spacer led to an increased degradation rate as expected [56]. 


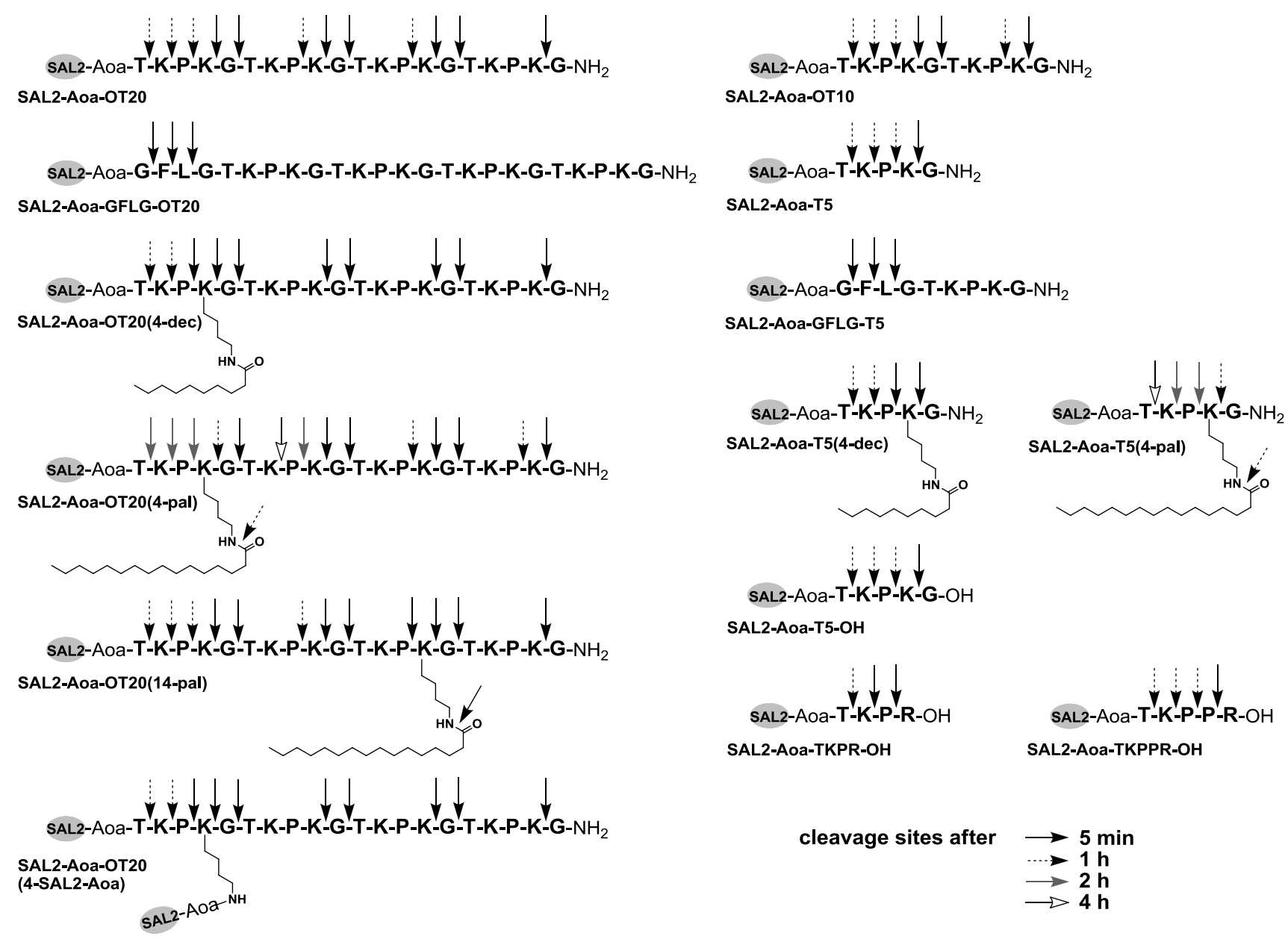

Figure 6. The detected cleavage sites during the degradation of SAL2-tuftsin conjugates in rat liver lysosomal homogenate.

\subsection{Intracellular antimycobacterial activity}

In vitro antimycobacterial activity of the compounds on extracellular M. tuberculosis $\mathrm{H}_{37} \mathrm{Rv}$ culture is important, but it is crucial that the compound is efficient against intracellular bacteria, too. Intracellular efficacy of salicylanilide-tuftsin conjugates was evaluated on infected MonoMac6 human monocytes. MonoMac6 was established as a cell line which appears to have phenotypic and functional characteristic of mature blood monocytes $[52,57,58]$. MonoMac6 cells are attached to the tissue culture plate's well surface without any treatment after hours as a homogeneous cell population. Therefore infected MonoMac6 cell line is frequently used as a host cell model to determine intracellular activity of antituberculars against phagocytosed intracellular bacteria [38, 42]. Monolayer of MonoMac6 was infected with M. tuberculosis $\mathrm{H}_{37} \mathrm{Rv}$. The infected cells were than treated with the free drugs and the conjugates using concentrations of $125 \mu \mathrm{M}$ and $250 \mu \mathrm{M}$. After 3 days the treatment was repeated with fresh solution of the compounds for an additional 3 days. Untreated infected cells were considered as negative control. The results are summarized in Figure 7.

INH was also tested and did not show antitubercular activity against intracellular bacteria even at 365 $\mu \mathrm{M}$ concentration [38]. The free salicylanilide derivatives did not exhibit intracellular antitubercular activity at none of the used concentrations. In contrast, most of the conjugates significantly reduced the colony forming units (CFU) of intracellular M. tuberculosis bacteria compared to untreated control in a concentration dependent manner. Among the OT20 conjugates SAL1-Aoa-OT20 was more effective than 
SAL2-Aoa-OT20 and SAL3-Aoa-OT20 at both concentrations. However, in the case of SAL1-Aoa-OT20(4pal) and SAL2-Aoa-OT20(4-pal) the activity was very similar. In terms of the length of the tuftsin derivatives at $125 \mu \mathrm{M}$ there is no significant difference, at $250 \mu \mathrm{M}$ the smallest SAL2-Aoa-T5 was the most effective followed by the longest SAL2-Aoa-OT20. SAL2-Aoa-OT10 resulted in approximately 5-times higher CFU than SAL2-Aoa-T5. The presence of the GFLG spacer in the case of most peptide has no influence on the activity, only in the case of SAL2-Aoa-TKPR-OH, the presence of the spacer reduced its activity 25-times (SAL2-Aoa-GFLG-TKPR-OH). At $250 \mu \mathrm{M}$ the SAL2-Aoa-T5 with amide on the Cterminal was 10-times more effective than its analogue SAL2-Aoa-T5-OH with carboxyl group on the Cterminal of the peptide. The same tendency can be observed in the case of the derivatives of these peptides with GFLG spacer (SAL2-Aoa-GFLG-T5 vs. SAL2-Aoa-GFLG-T5-OH). The OT20 derivative which contains two molecules of salicylanilides, SAL2-Aoa-OT20(4-SAL2-Aoa) showed a weaker activity than its analogue with only one drug molecule SAL2-Aoa-OT20. The conjugate TKPR-OT10(8-SAL2-Aoa; 13SAL2-Aoa) that contains also two salicylanilides has better activity than SAL2-Aoa-OT20(4-SAL2-Aoa). It was also more effective than SAL2-Aoa-OT20 and SAL2-Aoa-OT10 at $250 \mu \mathrm{M}$ concentration, but less effective than SAL2-Aoa-TKPR. SAL2-Aoa-OT20(4-but) has slightly better activity than SAL2-Aoa-OT20 conjugate without fatty acid side chain. The decanoic or palmitic acid side chain containing OT20 derivative (SAL2-Aoa-OT20(4-dec), SAL1-Aoa-OT20(4-pal), SAL2-Aoa-OT20(4-pal) and SAL2-Aoa-OT20(14-pal)) were outstandingly effective both at 125 and $250 \mu \mathrm{M}$ concentration. At $250 \mu \mathrm{M}$ SAL2-Aoa-OT20(4-pal) resulted in 5-times lower CFU value than its analogue where the palmitic acid is on the $14^{\text {th }}$ amino acid residue SAL2-Aoa-OT20(14-pal). In the case of the T5 derivatives both fatty acid containing conjugates SAL2-Aoa-T5(4-dec) and SAL2-Aoa-T5(4-pal) showed a better activity than SAL2-Aoa-T5 without fatty acid side chain. Interestingly at $125 \mu \mathrm{M}$ the decanoic acid containing derivative proved to be better than the palmitic acid containing one, but this result is reversed at $250 \mu \mathrm{M}$. The OT20 derivatives containing the fatty acids (SAL2-Aoa-OT20(4-dec) and SAL2-Aoa-OT20(4-pal)) showed a more improved effect in comparison with T5 derivatives SAL2-Aoa-T5(4-dec) and SAL2-Aoa-T5(4-pal). The smallest metabolites produced during lysosomal degradation, SAL2-Aoa-Thr-OH and SAL2-Aoa-Gly-OH, also showed an activity against the intracellular bacteria without dependence of concentration. They can reduce the CFU values similarly as e.g. conjugate SAL2-Aoa-OT10, SAL2-Aoa-TKPPR-OH or SAL2-Aoa-GFLG-TKPPR-OH (at $250 \mu \mathrm{M}$ ).

Taken together the results of the ability to inhibit intracellular bacteria and cytostatic activity of the compounds on the host cell MonoMac6, we can conclude that the conjugates showing cytostatic activity with $\mathrm{IC}_{50}$ value lower than $125 \mu \mathrm{M}$ can be cytostatic on MonoMac6 cells at the applied concentrations (125 $\mu \mathrm{M}$ and $250 \mu \mathrm{M})$. At the washing steps the dead cells with bacteria might be washed out, therefore decrease of CFU can be observed. However, the free salicylanilides also have cytostatic activity at these concentrations but the treatment with the free drug molecules did not reduce the CFU at all, the bacteria survive. Therefore, the activity of the conjugates against the intracellular bacteria cannot be attributed to their cytostatic activity to the host cells. They reduce the CFU probably because of their better intracellular availability. This could be due to the better cellular uptake rate of conjugates than the free drugs into the host cells. 


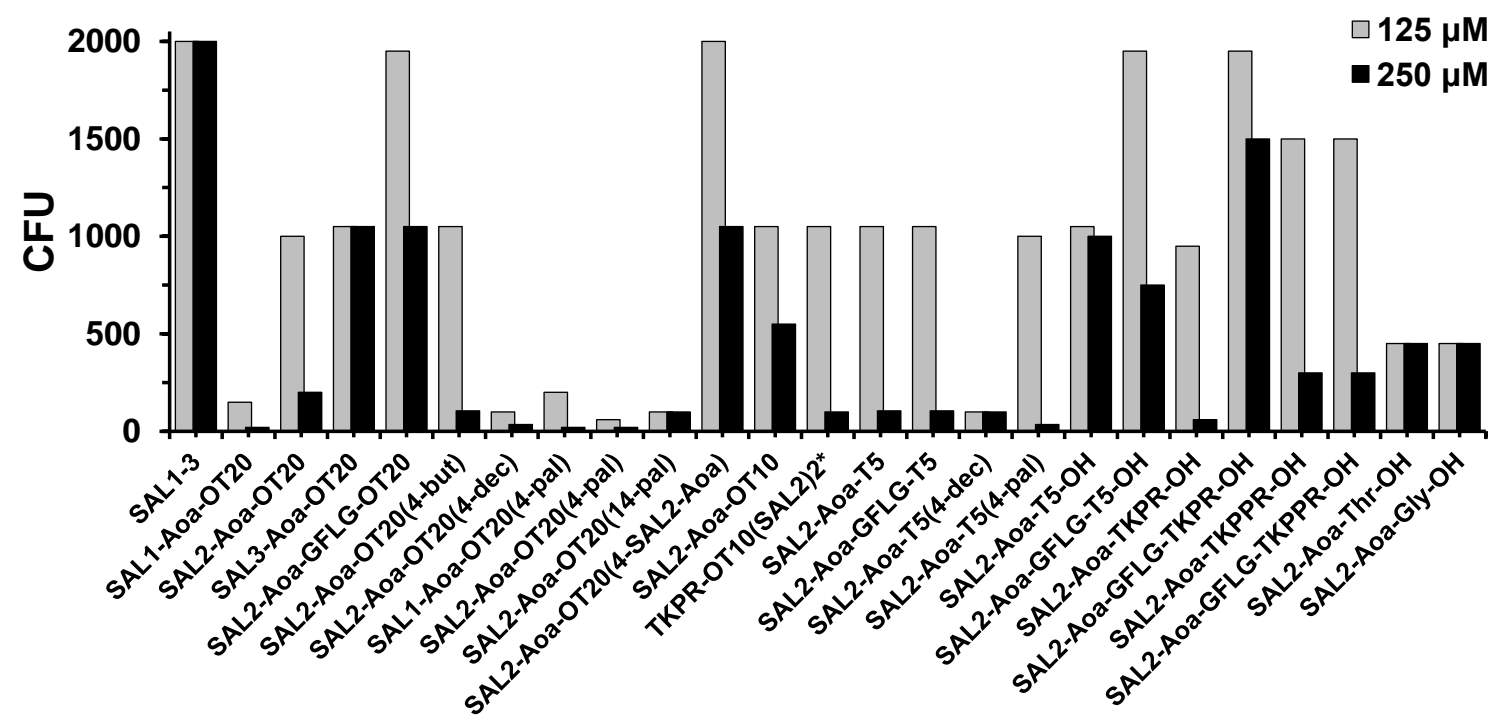

Figure 7. The in vitro activity of the free salicylanilides and their peptide conjugates on $M$. tuberculosis $\mathrm{H}_{37} \mathrm{Rv}$ infected host cell model MonoMac6 cells. *(TKPR-OT10(SAL2)2 = TKPR-OT10(8-SAL2-Aoa; $13-$ SAL2-Aoa)) 


\section{Conclusions}

The major goal of our work was to synthesize, chemically and biologically characterize salicylanilidetuftsin conjugates that have in vitro antimycobacterial activity especially against intracellular bacteria and increased cellular uptake rate on the host cell model.

The salicylanilide derivatives have outstanding in vitro antimycobacterial effect on the extracellular bacteria but their activity is overshadowed by their cytostatic activity against the host cell monocytes and against the hepatocytes. In the case of the salicylanilide-tuftsin conjugates this antimycobacterial activity is mostly preserved with the conjugation to peptides by oxime bond (Figure 8). Moreover there are conjugates that have MIC values only slightly higher than the MIC value of the free salicylanilide and these conjugates showed no cytostatic activity on the host cells, therefore the selectivity of the salicylanilide was enhanced successfully towards the bacteria. The common characteristic of these conjugates that they contain only one tuftsin unit with or without the presence of spacer (SAL2-Aoa-T5, SAL2-Aoa-GFLG-T5, SAL2-Aoa-T5OH, SAL2-Aoa-GFLG-T5-OH, SAL2-Aoa-TKPR-OH, SAL2-Aoa-GFLG-TKPR-OH, SAL2-Aoa-TKPPR$\mathrm{OH}$, and SAL2-Aoa-GFLG-TKPPR-OH).

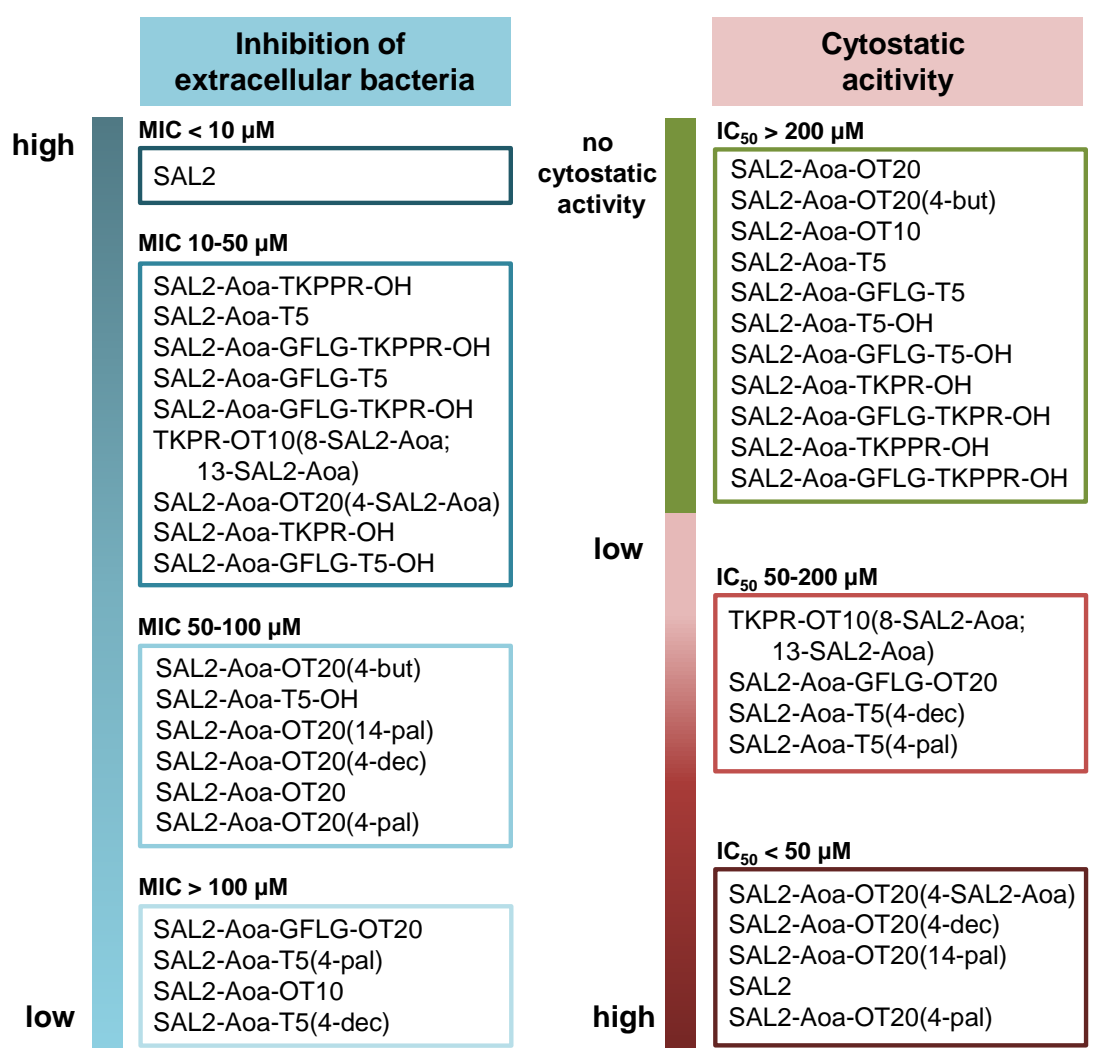

Figure 8. Sorting of the salicylanilide-tuftsin conjugates according to their inhibition ability on the extracellular bacteria and their cytostatic effect on MonoMac6 cells.

More importantly, all the conjugates decreased the enumerated colonies of the intracellular bacteria after cell lysis while the free salicylanilides were inactive. The improved intracellular efficacy of the conjugates on infected cells can be explained probably with the better internalization of the conjugated antitubercular drugs than the free drugs (Figure 9). We can estimate the internalization rate of the conjugates from the result of the cellular uptake study of the fluorescently labelled carriers. The inhibition effect against the intracellular bacteria is increasing with the estimated intracellular uptake rate in the case of most of the conjugates. Unfortunately, the conjugates that could have the highest cellular uptake rate and the highest 
activity against intracellular bacteria, possessed high or medium cytostatic activity. Their common property is that they have decanoic or palmitic acid side chain modification (SAL2-Aoa-OT20(4-dec), SAL2-AoaOT20(4-pal), SAL2-Aoa-OT20(14-pal), SAL2-Aoa-T5(4-dec), and SAL2-Aoa-T5(4-pal)). However, the decanoic acid containing monotuftsin conjugate, SAL2-Aoa-T5(4-dec) with moderate cytostatic activity and outstanding activity against intracellular bacteria is a favourable candidate for further investigation. Most of the non-cytostatic conjugates that have significant efficacy against the extracellular bacteria were also effective against the intracellular bacteria. The most promising ones among these conjugates are the SAL2Aoa-T5, SAL2-Aoa-GFLG-T5 and SAL2-Aoa-TKPR-OH monotuftsin derivatives.

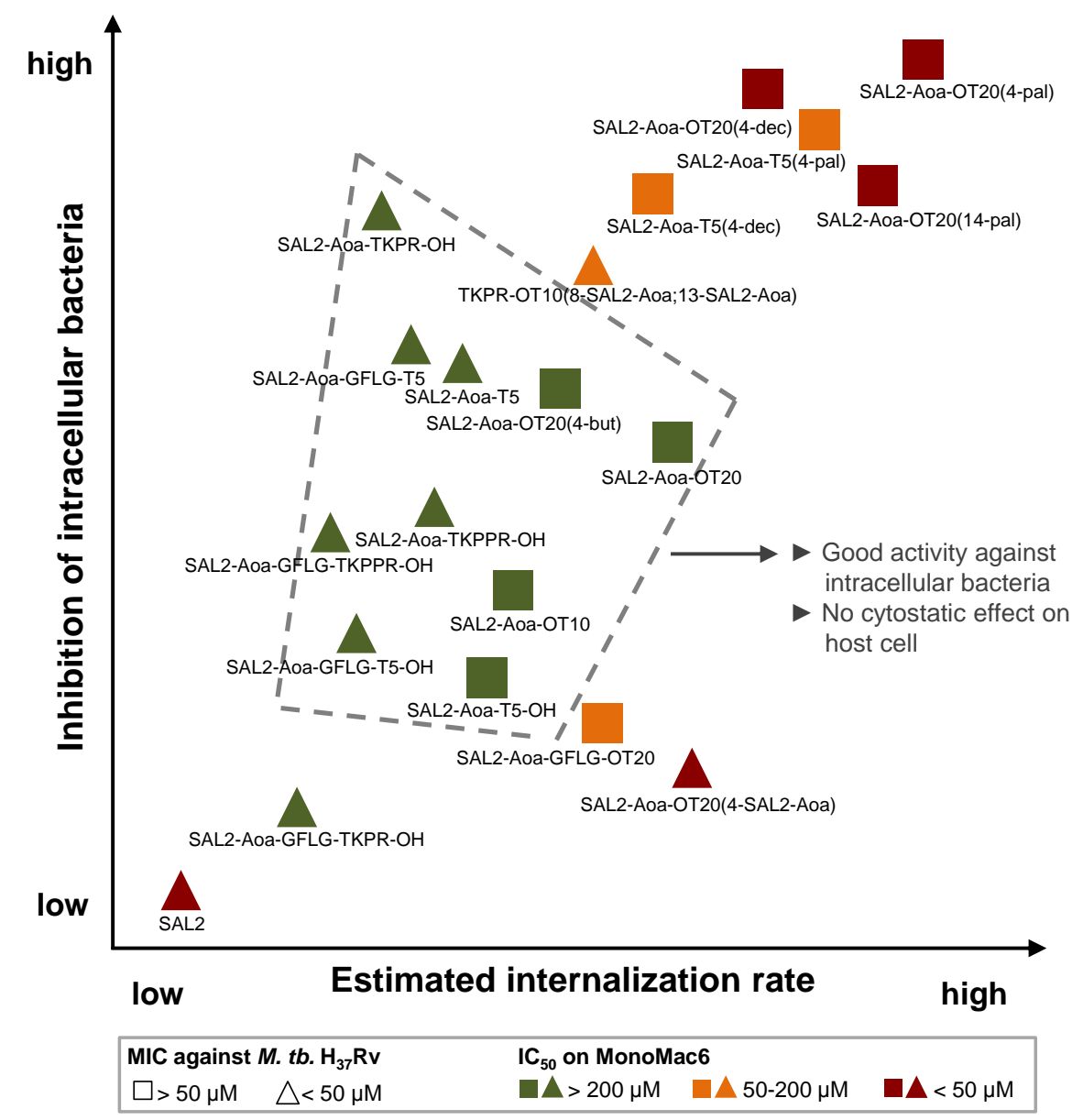

Figure 9. Map of the in vitro activity of the salicylanilide-tuftsin conjugates: correlation between the estimated internalization rate on MonoMac6 cells and the inhibition of intracellular bacteria. The efficacy on the extracellular bacteria and the cytostatic effect on MonoMac6 cells are also indicated.

As an indirect approach we have estimated the lipophilic-hydrophilic character of the conjugates using retention time obtained by high performance liquid chromatography. Our reference compounds were injected onto a C18 column. The retention time of compounds with known $\log \mathrm{P}$ values were used to predict the lipophilic character of the tuftsin conjugate. In the aspect of the in vitro antimycobacterial activity on intracellular bacteria and lipophilicity of the salicylanilides and conjugates there is no obvious correlation (Figure S28). The free salicylanilide derivatives with high lipophilicity were not effective against the intracellular bacteria. However, we can conclude that having increased lipophilic properties by decanoic or palmitic acid side chain modification outstandingly enhanced the cellular uptake rate of the carrier peptides along with the activity against the intracellular bacteria. Moreover, the most lipophilic conjugate, the 
palmitic acid side chain containing monotuftsin derivative (SAL2-Aoa-T5(4-pal)) was one of the most efficient in the aspect of the inhibition of the intracellular bacteria. Although, conjugates without fatty acid side chains therefore considered rather hydrophilic compounds also were able to significantly inhibit the intracellular bacteria without being cytostatic to the host cell model.

The conjugates regardless to their mostly hydrophilic characters probably have enhanced cellular uptake that can occur by receptor mediated endocytosis or phagocytosis. Increasing the lipophilicity can result enhanced non-specific transport (diffusion) through the cell membrane.

In the lysosomal homogenate the conjugates with the GFLG spacer have the highest degradation rate, they provide the smallest metabolite the soonest. The presence of the decanoic acid side chain modification increased, while the presence of the palmitic acid side chain modification decreased the degradation rate of the conjugates, and usually the stability of the shorter peptides are higher than the stability of the longer ones. However, the differences in the stability of the conjugates in lysosomal homogenate were not related with the intracellular activity, our intracellular model is not sensitive enough to see the effect of the different degradation pattern of the conjugates.

In summary we can conclude that the antimycobacterial activity of the salicylanilide derivatives is preserved in the conjugates; the minimal inhibitory concentration of the conjugates was similar to the free drugs or higher. Improved selectivity towards the bacteria was achieved with the conjugation of salicylanilides in most of the cases. It is highly important that the salicylanilide-peptide conjugates were effective against the intracellular bacteria in contrast with the free drugs, probably due to the better internalization rate of the conjugates than the free drugs. 


\section{Experimental Section}

\subsection{Chemistry}

\subsubsection{General Methods}

All reagents and solvents were purchased from Sigma-Aldrich and Merck. Commercial grade reagents were used without a further purification. Reactions were monitored by thin layer chromatography plates coated with $0.2 \mathrm{~mm}$ silica gel $60 \mathrm{~F}_{254}$ (Merck), which were visualized by UV irradiation (254 $\mathrm{nm}$ ). All melting points were determined on a Melting Point machine B-540 (Büchi) apparatus using open capillaries and they are uncorrected. Infrared spectra (KBr pellets) were recorded on FT-IR spectrometer Nicolet 6700 FT-IR (Thermo Fisher Scientific, Waltham, MA, USA) in the range of $400-4000 \mathrm{~cm}^{-1}$ using the ATR technique. The NMR spectra were measured at ambient temperature on a Varian VNMR S500 instrument (500 MHz for ${ }^{1} \mathrm{H}$ and $126 \mathrm{MHz}$ for ${ }^{13} \mathrm{C}$; Varian Comp. Palo Alto, CA, USA) using deuterated dimethyl sulfoxide $\left(\mathrm{DMSO}-d_{6}\right)$ solutions of the samples. The chemical shifts, $\delta$, are given in ppm, related to tetramethylsilane as an internal standard. The coupling constants $(J)$ are reported in Hz. Elemental analysis $(\mathrm{C}, \mathrm{H}, \mathrm{N})$ was performed on an automatic microanalyser CHNS-O CE instrument (FISONS EA 1110, Milano, Italy). Measured monoisotopic or average molecular mass was acquired by Bruker Esquire 3000+ ESI-MS. Samples were dissolved in a mixture of acetonitrile/water $=1 / 1(\mathrm{v} / \mathrm{v})$ containing $0.1 \%$ acetic acid and introduced by a syringe pump with a flow rate of $10 \mu \mathrm{L} / \mathrm{min}$.

\subsubsection{Synthesis of the salicylanilide derivatives}

Salicylanilides were prepared by the reaction of the appropriate substituted salicylic acids $(5 \mathrm{mmol})$ and the substituted anilines $(5 \mathrm{mmol})$ in the presence of phosphorus trichloride $(2.5 \mathrm{mmol})$ in chlorobenzene [46]. The reaction was carried out with vigorously stirring in a microwave reactor (MicroSYNTH MLS ETHOS 1600 URM) for $22 \mathrm{~min}$ to reflux. The reaction mixture was filtered while hot, let stand at $20^{\circ} \mathrm{C}$ and then at $4{ }^{\circ} \mathrm{C}$ for $24 \mathrm{~h}$. The crude product was filtered off and he mother liquor was partly evaporated to the crystallization to obtain the second portion of crude product. The crude product was suspended in $5 \%$ sodium bicarbonate water solution and stirred until cessation of $\mathrm{CO}_{2}$ was observed. The crystals were filtered off and then suspended in $0.1 \mathrm{M} \mathrm{HCl}$. The mixture was filtered off, washed with distilled water and the obtained pure product was dried.

\section{$N$-(4-Acetylphenyl)-5-chloro-2-hydroxybenzamide (SAL1)}

Yellowish solid; yield: $7 \%$; mp: 231-233 ${ }^{\circ} \mathrm{C}$. IR (ATR): 3322, 1677, 1642, 1591, 1538, 1483, 1415, 1357, 1324, 1277, 1222, 1181, 1137, 1104, 967, 907, 843, 825, 700, 670, 652. ${ }^{1} \mathrm{H}$ NMR (500 MHz, DMSO): $\delta$ $11.64(1 \mathrm{H}, \mathrm{bs}, \mathrm{OH}), 10.62(1 \mathrm{H}, \mathrm{bs}, \mathrm{NH}), 7.97\left(2 \mathrm{H}, \mathrm{d}, J=8.6 \mathrm{~Hz}, \mathrm{H} 3{ }^{\prime}, \mathrm{H} 5^{\prime}\right), 7.89$ (1H, d, $\left.J=2.7 \mathrm{~Hz}, \mathrm{H} 6\right)$, $7.86\left(2 \mathrm{H}, \mathrm{d}, J=8.7 \mathrm{~Hz}, \mathrm{H} 2^{\prime}, \mathrm{H}^{\prime}\right), 7.46(1 \mathrm{H}, \mathrm{dd}, J=8.8 \mathrm{~Hz}, J=2.7 \mathrm{~Hz}, \mathrm{H} 4), 7.03(1 \mathrm{H}, \mathrm{d}, J=8.8 \mathrm{~Hz}, \mathrm{H} 3)$, $2.55\left(3 \mathrm{H}, \mathrm{s}, \mathrm{CH}_{3}\right) .{ }^{13} \mathrm{C}$ NMR (126 MHz, DMSO): $\delta 196.75,165.09,156.46,142.71,133.23,132.60,129.55$, 129.36, 128.85, 123.01, 119.93, 119.19, 26.67. $\mathrm{Mw}_{\text {monoizotopic }}$ (calc/meas): 289.1 / 289.1. Anal. Calcd. for $\mathrm{C}_{15} \mathrm{H}_{12} \mathrm{ClNO}_{3}$ (289.71): C, 62.19; H, 4.18; N, 4.83; Found: C, 62.02; H, 4.19; N, 4.74.

\section{$N$-(4-Acetylphenyl)-5-bromo-2-hydroxybenzamide (SAL2)}

Yellowish solid; yield: $6 \%$; mp: 243-245 ${ }^{\circ} \mathrm{C}$. IR (ATR): 3335, 1671, 1637, 1530, 1482, 1414, 1359, 1332, 1270, 1221, 1182, 1140, 1096, 962, 909, 820, 778, 658. ${ }^{1} \mathrm{H}$ NMR (500 MHz, DMSO): $\delta 11.64$ (1H, bs, OH), $10.62(1 \mathrm{H}, \mathrm{bs}, \mathrm{NH}), 8.01(1 \mathrm{H}, \mathrm{d}, J=2.5 \mathrm{~Hz}, \mathrm{H6}), 7.97\left(2 \mathrm{H}, \mathrm{d}, J=8.6 \mathrm{~Hz}, \mathrm{H} 3{ }^{\prime}, \mathrm{H} 5\right.$ '), $7.85(2 \mathrm{H}, \mathrm{d}, J=8.6 \mathrm{~Hz}$, 
H2', H6'), $7.57(1 \mathrm{H}, \mathrm{dd}, J=8.8 \mathrm{~Hz}, J=2.6 \mathrm{~Hz}, \mathrm{H} 4), 6.97(1 \mathrm{H}, \mathrm{d}, J=8.8 \mathrm{~Hz}, \mathrm{H} 3), 2.55\left(3 \mathrm{H}, \mathrm{s}, \mathrm{CH}_{3}\right) .{ }^{13} \mathrm{C}$ NMR (126 MHz, DMSO): $\delta$ 196.75, 165.02, 156.86, 142.70, 136.03, 132.59, 131.69, 129.54, 121.02, 119.92, 119.60, 110.41, 26.67. $\mathrm{Mw}_{\text {monoizotopic }}$ (calc/meas): 333.0 / 333.1. Anal. Calcd. for $\mathrm{C}_{15} \mathrm{H}_{12} \mathrm{BrNO}_{3}$ (334.16): C, 53.91; H, 3.62; N, 4.19; Found: C, 54.01; H, 3.59; N, 4.22.

\section{5-Formyl-2-hydroxy- $\boldsymbol{N}$-[4-(trifluoromethyl)phenyl]benzamide (SAL3)}

Yellowish solid; yield: $6 \%$; mp: $254.5-257^{\circ} \mathrm{C}$. IR (ATR): 3343, 1685, 1637, 1608, 1588, 1551, 1487, 1370, 1332, 1307, 1295, 1243, 1196, 1184, 1152, 1101, 1081, 1066, 1017, 964, 879, 852, 824, 678. ${ }^{1} \mathrm{H}$ NMR (500 MHz, DMSO): $\delta 12.29(1 \mathrm{H}, \mathrm{bs}, \mathrm{OH}), 10.74(1 \mathrm{H}, \mathrm{s}, \mathrm{NH}), 9.90(1 \mathrm{H}, \mathrm{s}, \mathrm{COH}), 8.40(1 \mathrm{H}, \mathrm{d}, J=2.1 \mathrm{~Hz}, \mathrm{H} 6)$, 7.97-7.93 (3H, m, H4, H3', H5') $7.74\left(2 \mathrm{H}, \mathrm{d}, J=8.5 \mathrm{~Hz}, \mathrm{H} 2^{\prime}, \mathrm{H} 6{ }^{\prime}\right), 7.17(1 \mathrm{H}, \mathrm{d}, J=8.5 \mathrm{~Hz}, \mathrm{H} 3){ }^{13} \mathrm{C}$ NMR (126 MHz, DMSO): $\delta$ 191.12, 165.60, 162.58, 142.13, 133.99, 132.86, 128.43, 126.26 (q, $J=3.8 \mathrm{~Hz}$ ), 124.52 (q, $J=272.0 \mathrm{~Hz}), 124.24$ (q, $J=32.1 \mathrm{~Hz}), 120.57,120.27,118.01 . \mathrm{Mw}_{\text {monoizotopic }}$ (calc/meas): $309.1 /$ 309.1. Anal. Calcd. for $\mathrm{C}_{15} \mathrm{H}_{10} \mathrm{~F}_{3} \mathrm{NO}_{3}$ (309.24): C, 58.26; H, 3.26; N, 4.53; Found: C, 58.34; H, 3.40; N, 4.48.

\subsubsection{Synthesis of the tuftsin derivatives}

\section{General method of peptide synthesis}

The tuftsin derivatives with amide on the C-terminal were synthesised by solid-phase peptide synthesis on Fmoc-Rink Amide MBHA resin; in the case of tuftsin derivatives with carboxyl group on the Cterminal Wang resin was used. The peptides were prepared in an automated peptide synthesizer (Syro-I, Biotage, Uppsala, Sweden) or manually using Fmoc/tBu strategy. In the case of the coupling of the first amino acid to the Wang resin 2 equiv. of Fmoc-amino acid derivative, 2 equiv. of DIC and 0.2 equiv. of DMAP (4-(dimethylamino)pyridine) dissolved in NMP was used (60 min).

The protocol of the synthesis was the following: (i) Fmoc deprotection in the case of automated synthesizer with 20\% piperidine/DMF (v/v), $2 \mathrm{~min}, 20 \mathrm{~min}$; in the case of manual synthesis with $2 \% \mathrm{DBU}$, 2\% piperidine/DMF (v/v), $2 \mathrm{~min}, 2 \mathrm{~min}, 5 \mathrm{~min}, 10 \mathrm{~min}$; (ii) washing with DMF (5 x $1 \mathrm{~min}$ ); (iii) coupling twice with 4 equiv. of Fmoc-amino acid derivative-DIC-HOBt dissolved in NMP ( 2 x 60 min, automated synthesizer) or 3 equiv. of Fmoc-amino acid derivative-DIC-HOBt dissolved in NMP (1 x 60 min, manual synthesis); and (iv) washing with DMF (5 x 1 min).

Peptides were cleaved from the resin with the TFA/ $\mathrm{H}_{2} \mathrm{O} / \mathrm{TIS}(9.5: 2.5: 2.5 \mathrm{v} / \mathrm{v})$ mixture $(2.5 \mathrm{~h}, \mathrm{RT})$. After filtration, compounds were precipitated in cold diethyl ether, centrifuged (4000 rpm, $5 \mathrm{~min}$ ), and freeze-dried in water. Crude acetylated and 5(6)-carboxyfluorescein containing products were purified by semi-preparative RP-HPLC as described below. Purified peptides were analysed by analytical RP-HPLC, ESI-MS, and amino acid analysis. Crude Aoa-tuftsin derivatives were used for conjugation without purification.

\section{Synthesis of the tuftsin derivatives without side chain modification}

In the case of the tuftsin derivatives without any side chain modification Boc-Aoa-OH (3 equiv., DIC, $\mathrm{HOBt}$, in NMP, $60 \mathrm{~min}$ ) was coupled to the $\mathrm{N}$-terminal of the peptides on the resin to get the (aminooxy)acetylated derivatives. The acetylated control peptides were produced by acetylation of the $\mathrm{N}$ terminal of the peptides on the resin using acetic anhydride/DIEA/DMF (1:1:2 v/v) for $60 \mathrm{~min}$. In the case of labelling the $\mathrm{N}$-terminal with 5(6)-carboxyfluorescein a mixture of 3 equiv. 5(6)-carboxyfluorescein, HOBt and DIC in NMP was added to the peptide-resin and after $60 \mathrm{~min}$, the resin was washed and treated with $20 \%$ piperidine in DMF for 5 and $30 \mathrm{~min}$. This step is necessary because 5(6)-carboxyfluorescein contains unprotected hydroxyl group in the molecule, thus extra 5(6)-carboxyfluorescein molecules can couple to the 
hydroxyl group of the 5(6)-carboxyfluorescein coupled directly to the peptide [59]. When these steps were not carried out, compounds containing two or three extra units of 5(6)-carboxyfluorescein were observed in the crude product. The peptides were cleaved from the resin as described above.

\section{Synthesis of the tuftsin derivatives with side chain modification}

In the case of the tuftsin derivatives with side chain modification Fmoc-Lys(Boc)-OH was replaced by Fmoc-Lys(Dde)-OH in the required position. After the final Fmoc-deprotection Boc-Aoa-OH (3 equiv., DIC, HOBt, in NMP, $60 \mathrm{~min}$ ) or 5(6)-carboxyfluorescein (3 equiv., DIC, HOBt, in NMP 60 min, followed by $5+$ $30 \mathrm{~min} 20 \%$ piperidine treatment) was coupled to the N-terminal of the peptides. The acetylated peptides were produced by acetylation of the N-terminal using acetic anhydride/DIEA/DMF (1:1:2 v/v) for $60 \mathrm{~min}$. After the derivatization of the N-terminal, the 1-(4,4-dimethyl-2,6-dioxocyclohex-1-yldine)ethyl (Dde) protecting group of the Lys side chain amino group was selectively removed using $2 \%$ hydrazine hydrate in DMF (v/v) (6 x $2 \mathrm{~min})$, followed by washing with DMF ( $5 \times 1 \mathrm{~min})$. To the free $\varepsilon$-amino group of the Lys residue Boc-Aoa-OH or 5(6)-carboxyfluorescein or the appropriate fatty acid was coupled. In the case of butyric acid coupling of 3 equiv. of butyric anhydride, 3 equiv. of DIEA in DMF was used (60 min). In the case of decanoic acid and palmitic acid 3 equiv. of the corresponding fatty acid with 3 equiv. of HOBt, 3 equiv. of DIC in NMP was used (60 min). The peptides were cleaved from the resin as described above.

\section{Synthesis of (aminooxy)acetyl-amino acid derivatives (Aoa-Thr-OH, Aoa-Gly-OH and H-Lys(Aoa)- OH)}

Aoa-Thr-OH. Aoa-Gly-OH and H-Lys(Aoa)-OH were synthetized by solid-phase peptide synthesis on Wang resin manually using Fmoc/tBu strategy. Fmoc-Thr( $t \mathrm{Bu})-\mathrm{OH}$, Fmoc-Gly-OH or Boc-Lys(Fmoc)-OH was coupled (2 equiv. of protected-amino acid derivative, 2 equiv. of DIC and 0.2 equiv. of DMAP, in NMP, $60 \mathrm{~min}$ ) to the resin, Fmoc protecting group was removed (2\% DBU, 2\% piperidine/DMF (v/v), 2, 2, 5, 10 $\mathrm{min}$ ) and Boc-Aoa-OH was coupled (3 equiv., DIC, HOBt, in NMP, $60 \mathrm{~min}$ ). The (aminooxy)acetyl amino acid derivatives were cleaved from the resin with the TFA/ $\mathrm{H}_{2} \mathrm{O} / \mathrm{TIS}(9.5: 2.5: 2.5 \mathrm{v} / \mathrm{v})$ mixture $(2.5 \mathrm{~h}, \mathrm{RT})$. After filtration, majority of the TFA was removed by rotary evaporation, and the crude product was freezedried in water. Crude Aoa-amino acid derivatives were used for conjugation without purification.

\section{Reverse-Phase High-Performance Liquid Chomatography (RP-HPLC)}

Analytical RP-HPLC was performed on Exformma HPLC system (Wufeng Scientific Instrument, Sanghai, China) using an Agilent Zorbax SB-C18 column $(5 \mu \mathrm{m}, 100 \AA$, $4.6 \mathrm{~mm}$ x $150 \mathrm{~mm}$ ) (Agilent Technologies, Santa Clara, CA, United States). Gradient elution (0-5 min 0\% B, 5-15 min 0-60\% B, 15-25 $\min 60-100 \% \mathrm{~B}, 25-29 \min 100 \% \mathrm{~B}$ ) was used with the following eluents: $0.1 \% \mathrm{TFA} /$ water v/v (A eluent), $0.1 \%$ TFA/acetonitrile-water 80:20 v/v (B eluent). The flow rate was $1 \mathrm{~mL} / \mathrm{min}$ at ambient temperature, and the peaks were detected at $220 \mathrm{~nm}$.

The crude peptides and conjugates were purified on a semi-preparative Phenomenex Jupiter Proteo C18 column (10 $\mathrm{m}, 90 \AA, 10$ x $250 \mathrm{~mm}$ ) (Torrance, CA, USA). The applied flow rate was $4 \mathrm{~mL} / \mathrm{min}$ at ambient temperature, and the peaks were detected at $220 \mathrm{~nm}$. The same eluents as described above with an appropriate linear gradient were applied.

\section{Electrospray Ionization Mass Spectrometry (ESI-MS)}

ESI-MS was performed on a Bruker Esquire 3000+ ion trap mass spectrometer (Bremen, Germany), operating in continuous sample injection mode at $10 \mu \mathrm{L} / \mathrm{min}$ flow rate. Samples were dissolved in $50 \%$ 
acetonitrile/50\% water containing $0.1 \%$ acetic acid (v/v). Mass spectra were recorded in positive or negative ion mode in the $\mathrm{m} / \mathrm{z}$ 50-1500 range.

\subsubsection{Conjugation of salicylanilides to tuftsin derived carrier peptides}

Salicylanilide compounds, which contain carbonyl group, were conjugated to the (aminooxy)acetylated tuftsin derivatives. The conjugations via oxime bond were carried out under acidic condition $(\mathrm{pH} 4.5)$ in a mixture of $0.2 \mathrm{M}$ sodium acetate buffer and 2-methoxyethanol, at a peptide concentration of $5-10 \mathrm{mg} / \mathrm{mL}$. Salicylanilide derivatives were used in $10 \%$ excess as compared to the (aminooxy)acetyl derivatives of the tuftsin peptides. The reaction mixtures were stirred for $24-72 \mathrm{~h}$ at room temperature and monitored by analytical RP-HPLC. The conjugates were purified by semi-preparative RPHPLC and lyophilized. The purified conjugates were characterized by analytical RP-HPLC and mass spectrometry.

\subsection{Determination of in vitro antimycobacterial activity}

In vitro antimycobacterial activity of the compounds was determined on slow growing Mycobacterium tuberculosis $\mathrm{H}_{37} \mathrm{Rv}$ (ATCC 27294) and Mycobacterium tuberculosis A8 MDR strain (ATCC 35822, resistant to isoniazid, and rifampicin), and on fast growing Mycobacterium abscessus strain (ATCC 19977), by serial dilution in Sula semisynthetic medium, which was prepared in-house (pH 6.5) [60, 61]. Compounds were added to the medium as DMSO solutions at various doses (range of final concentration was between 0.05 and $400 \mu \mathrm{g} / \mathrm{mL}$ ). Minimal inhibitory concentrations (MIC) were determined after incubation at $37{ }^{\circ} \mathrm{C}$ for 21 or 28 days in the case of M. tuberculosis $\mathrm{H}_{37} \mathrm{Rv}$, for 28 days in the case of A8 MDR, and for 7 days in the case of M. abscessus. MIC was the lowest concentration of a compound at which the visible inhibition of the growth of M. abscessus, M. tuberculosis $\mathrm{H}_{37} \mathrm{Rv}$ and A8 MDR strain occurred. In order to confirm the growth inhibition, colony forming unit ( $\mathrm{CFU}$, the number of the colonies that developed from the viable bacteria) was determined by subculturing from the Sula medium onto drug-free Löwenstein-Jensen solid medium. Samples were incubated for further 28 days in the case of $M$. tuberculosis $\mathrm{H}_{37} \mathrm{Rv}$ and A8 MDR, and for 7 days in the case of M. abscessus. Experiments were repeated at least two times. Isoniazid (INH), gentamicin (GEN) and ciprofloxacin (CIPX) were involved as reference antimycobacterial drugs.

\subsection{Determination of in vitro cytostatic and cytotoxic activity}

The in vitro cytostatic activity of the compounds was determined on MonoMac6 and HepG2 cells. MonoMac6 cell cultures (DSMZ no.: ACC 124, Deutsche Sammlung von Mikroorganismen and Zellkulturen GmbH, Braunschweig, Germany) and HepG2 cell cultures (ATCC HB-8065) were maintained in RPMI-1640 medium containing 10\% FCS, $2 \mathrm{mM} \mathrm{L}$-glutamine, and $160 \mu \mathrm{g} / \mathrm{mL}$ gentamicin at $37{ }^{\circ} \mathrm{C}$ in $5 \%$ $\mathrm{CO}_{2}$ atmosphere. The cells were plated on 96 -well plates one day before the treatment $(5000$ cells $/ 1 \mathrm{~mL}$ medium/well). After $24 \mathrm{~h}$ incubation at $37{ }^{\circ} \mathrm{C}$, cells were treated for $24 \mathrm{~h}$ (overnight) with the compounds dissolved in serum free RPMI-1640 medium $\left(\mathrm{c}_{\mathrm{DMSO}}=1.0 \% \mathrm{v} / \mathrm{v}\right)$ at $1 \times 10^{-3}$ to $200 \mu \mathrm{M}$ concentration range. Control cells were treated with serum free medium only or with DMSO containing serum free medium $\left(c_{\text {DMSO }}=1.0 \% \mathrm{v} / \mathrm{v}\right)$ at $37{ }^{\circ} \mathrm{C}$. After the treatment and incubation, cells were washed twice with serum free medium (centrifugation: $1000 \mathrm{rpm}, 5 \mathrm{~min}$ ). To determine the in vitro cytostatic effects, the cells were cultured for a further $72 \mathrm{~h}$ in serum containing medium. The cell viability was determined with $(4,5-$ dimethylthiazol-2-yl)-2,5-diphenyltetrazolium bromide (MTT)-assay. $45 \mu \mathrm{L}$ MTT solution (2 mg/mL) was added to each well (final concentration $367 \mu \mathrm{g} / \mathrm{mL}$ ) and during $3.5 \mathrm{~h}$ incubation purple formazan crystals were formed by mitochondrial dehydrogenase enzyme present in the living cells. After incubation cells were 
centrifuged for $5 \mathrm{~min}$ at $2000 \mathrm{rpm}$ and the supernatant was removed. The obtained formazan crystals were dissolved in DMSO and the optical density (OD) of the samples was determined at $\lambda=540$ and $620 \mathrm{~nm}$ using an ELISA Reader (Labsystems iEMS reader, Helsinki, Finland). The $\mathrm{OD}_{620}$ values were subtracted from the $\mathrm{OD}_{540}$ values. The percent of cytostasis was calculated using the following equation: 'cytostatic effect $(\%)=$ $100 \times\left[1-\left(\mathrm{OD}_{\text {treated }} / \mathrm{OD}_{\text {control }}\right)\right]$ ', where $\mathrm{OD}_{\text {treated }}$ and $\mathrm{OD}_{\text {control }}$ correspond to the optical densities of treated and control cells, respectively. In each case two independent experiments were carried out with 4 parallel measurements. The $50 \%$ inhibitory concentration $\left(\mathrm{IC}_{50}\right)$ values were determined from the dose-response curves. The curves were defined using Microcal ${ }^{\mathrm{TM}}$ Origin1 (version 7.5) software.

The in vitro cytotoxic activity of the selected compounds was determined on murine bone marrowderived macrophages $(\mathrm{BMM} \Phi)$. The cells were prepared and differentiated as described in the literature [62], licence: XIV-I-001/2149-4/2012. The cells were plated on 96-well plates one day before the treatment $(10$ 000 cells $/ 1 \mathrm{~mL}$ medium/well). After $24 \mathrm{~h}$ incubation at $37^{\circ} \mathrm{C}$, cells were treated for $48 \mathrm{~h}$ with the compounds dissolved in serum free RPMI-1640 medium $\left(\mathrm{c}_{\mathrm{DMSO}}=1.0 \% \mathrm{v} / \mathrm{v}\right)$ at $1 \times 10^{-3}$ to $100 \mu \mathrm{M}$ concentration range. Control cells were treated with serum free medium only or with DMSO containing serum free medium $\left(c_{\text {DMSO }}=1.0 \% \mathrm{v} / \mathrm{v}\right)$ at $37{ }^{\circ} \mathrm{C}$. After the treatment and incubation, cells were washed twice with serum free medium (centrifugation: $1000 \mathrm{rpm}, 5 \mathrm{~min}$ ). To measure the in vitro cytotoxicity of the compounds, the MTT assay (as described above) was performed immediately after the washing step following the $48 \mathrm{~h}$ treatment.

\subsection{Determination of the pH dependence of the fluorescence intensity of the fluorescently labelled tuftsin derivatives}

Prior to the cellular uptake studies the $\mathrm{pH}$ dependence of the fluorescence intensity of the fluorescently labelled tuftsin derivatives was studied using Varian Cary Eclipse Fluorescence Spectrophotometer (Agilent Technologies, Santa Clara, CA, USA). Stock solutions in distilled water with $5 \mathrm{mM}$ compound concertation were prepared and then diluted to $50 \mu \mathrm{M}$ with the appropriate citric acid $-\mathrm{Na}_{2} \mathrm{HPO}_{4}$ buffer in a $3 \mathrm{~mL}$ cuvette. In the case of Cf-T5(4-pal) that has poor solubility in water $2.5 \mathrm{mM}$ stock solution was prepared with DMSO : distilled water 1:1 v/v, after dilution the final DMSO content was $1 \% \mathrm{v} / \mathrm{v}$. Five solutions with different $\mathrm{pH}$ values were used $(\mathrm{pH} \mathrm{4,} \mathrm{5,} \mathrm{6,} 7$ and 7.6). Supporting Information Table S6 shows the volumes of the $0.1 \mathrm{M}$ citric acid and $0.2 \mathrm{M} \mathrm{Na}_{2} \mathrm{HPO}_{4}$ that were needed for the preparation of the buffers with different $\mathrm{pH}$. As excitation wavelength $488 \mathrm{~nm}$ was used and the emission was measured between 490 and $700 \mathrm{~nm}$, $450 \mathrm{~V}$ detector voltage was used.

\subsection{Cellular uptake experiments}

The measurement of cellular uptake of the fluorescently labelled tuftsin derivatives was evaluated by flow cytometry (BD LSR II, BD Biosciences, San Jose, CA, USA) and fluorescent microscopy (Olympus CKX41, Hamburg, Germany, Olympus U-RFLT50 mercury-vapor lamp, WideBlue DM500 BP460-490 BA520 IF filter, objective: 40X) on MonoMac6 human monocytic cell line. Cells were harvested in the logarithmic phase of growth and plated on a 24 -well tissue culture plate $\left(10^{5}\right.$ cells/ $1 \mathrm{~mL}$ medium/well $) 24$ hours prior to the experiment. Fluorescently labelled tuftsin derivatives were dispersed in serum free RPMI medium and running dilutions were prepared. Applied concentration of the compounds on the cells was 0.32 , 1.6, 8, 40 and $200 \mu \mathrm{M}$. Cells were incubated with compounds for $3 \mathrm{~h}\left(37^{\circ} \mathrm{C}, 5 \% \mathrm{CO}_{2}\right.$ atmosphere). After centrifugation (1000 rpm, $5 \mathrm{~min}$ ) supernatant was removed and $100 \mu \mathrm{L} 1 \mathrm{mM}$ trypsin was added to the cells. After 1 min incubation at $37{ }^{\circ} \mathrm{C}$ the effect of trypsin was stopped by $800 \mu \mathrm{L}$ HPMI medium (HPMI; $100 \mathrm{mM}$ $\mathrm{NaCl}, 5.4 \mathrm{mM} \mathrm{KCl}, 0.4 \mathrm{mM} \mathrm{MgCl}_{2}, 0.04 \mathrm{mM} \mathrm{CaCl}_{2}, 10 \mathrm{mM}$ HEPES, $20 \mathrm{mM}$ glucose, $24 \mathrm{mM} \mathrm{NaHCO}$ and $5 \mathrm{mM} \mathrm{Na}_{2} \mathrm{HPO}_{4}$ at $\mathrm{pH}=7.4$ ) containing $10 \% \mathrm{FCS}$, and the cells were transferred from the plate to FACS- 
tubes. Cells were centrifuged (1000 rpm, $5 \mathrm{~min}$ ) and the supernatant was removed. After this procedure, cells were resuspended in $500 \mu \mathrm{L}$ HPMI, and the intracellular fluorescence intensity of MonoMac6 cells was measured (488 $\mathrm{nm}$ (Coherent Sapphire, $22 \mathrm{~mW}$ ) laser, channel PE LP550 (emission at $\lambda=550 \mathrm{~nm}$ )) which is proportional to the cellular uptake. Data were analysed with FACSDiva 5.0 software (BD Biosciences, San Jose, CA, USA). All measurements were performed in duplicates. Parallel with flow cytometry measurements microscopic image of the cells were captured with an Olympus CKX41 microscope.

The cellular uptake of the fluorescently labelled tuftsin derivatives was also studied on murine bone marrow-derived macrophages $(B M M \Phi)$. The cells were prepared and differentiated as described in the literature [62], licence: XIV-I-001/2149-4/2012. The steps of the protocol of the uptake study are the same as described above.

\subsection{Membrane integrity studies by propidium iodide staining}

PI staining was used to compare the effect of the control tuftsin peptides with or without fatty acid side chains (Ac-OT20, Ac-OT20(4-dec), Ac-OT20(4-pal) and Ac-OT20(14-pal)) to the cell membrane integrity using flow cytometry and fluorescent microscopy on MonoMac6 human monocytic cell line. Cells were harvested in the logarithmic phase of growth and plated on a 24 -well tissue culture plate $\left(10^{5}\right.$ cells/ $1 \mathrm{~mL}$ medium/well) 24 hours prior to the experiment. Acetylated tuftsin derivatives were dispersed in serum free RPMI medium and running dilutions were prepared. Applied concentration of the compounds on the cells was 8,40 and $200 \mu \mathrm{M}$. Cells were incubated with compounds for $3 \mathrm{~h}\left(37^{\circ} \mathrm{C}, 5 \% \mathrm{CO}_{2}\right.$ atmosphere). After centrifugation (1000 rpm, $5 \mathrm{~min}$ ) supernatant was removed and $100 \mu \mathrm{L} 1 \mathrm{mM}$ trypsin was added to the cells. After 1 min incubation at $37{ }^{\circ} \mathrm{C}$ the effect of trypsin was stopped by $800 \mu \mathrm{L}$ HPMI containing $10 \%$ FCS, and the cells were transferred from the plate to FACS-tubes. Cells were centrifuged (1000 rpm, $5 \mathrm{~min})$ and the supernatant was removed. After this procedure, cells were resuspended in $500 \mu \mathrm{L}$ HPMI. The cell viability and intracellular fluorescence intensity of MonoMac6 cells was determined by BD LSR II (488 nm (Coherent Sapphire, $22 \mathrm{~mW}$ ) laser, channel PE LP550 (emission at $\lambda=550 \mathrm{~nm}$ )) before and after adding 10 $\mu \mathrm{L} 50 \mu \mathrm{g} / \mathrm{mL}$ propidium-iodide solution. Data were analysed with FACSDiva 5.0 software. All measurements were performed in duplicates. Parallel with flow cytometry measurements microscopic image of the cells were captured with an Olympus CKX41 microscope (Olympus U-RFLT50 mercury-vapor lamp, SuperWideGreen DM570 BP480-550 BA590 IF filter, objective: 40X).

\section{7. Degradation of SAL2-tuftsin conjugates in rat liver lysosomal homogenate and HPLC-MS analysis}

The rat liver lysosomal homogenate was prepared as described previously [56]. The protein concentration was determined by Pierce BCA protein assay (bicinchoninic acid) according to the manufacturer's protocol (Thermo Fisher Scientific, Rockford, IL, USA) and it was $16.6 \mu \mathrm{g} / \mu \mathrm{L}$.

The degradation of the SAL2-tuftsin conjugates in the rat liver lysosomal homogenate was determined as follows: $90 \mu \mathrm{L}$ of $50 \mu \mathrm{M}(50 \mathrm{pmol} / \mu \mathrm{L})$ conjugate solutions were prepared with $0.2 \mathrm{M}$ sodium acetate buffer, $\mathrm{pH} 5.0$ and the appropriate amount of lysosomal homogenate was added to them to get the conjugates: lysosomal homogenate ratio $=1: 1, \mathrm{w} / \mathrm{w}$. The reaction mixtures were incubated at $37{ }^{\circ} \mathrm{C}$ and aliquots of $13 \mu \mathrm{L}$ were taken at $5 \mathrm{~min}, 1,2,4,8$ and $24 \mathrm{~h}$. The reactions were quenched by adding $2 \mu \mathrm{L}$ of acetic acid and followed by HPLC-MS analysis. Control experiments were performed with solutions of conjugates in $0.2 \mathrm{M}$ sodium acetate buffer, $\mathrm{pH} 5$ with $50 \mu \mathrm{M}$ conjugate concentration, which were incubated at $37{ }^{\circ} \mathrm{C}$ for $24 \mathrm{~h}$ and then also analysed by HPLC-MS. Lysosomal homogenate control in $0.2 \mathrm{M}$ sodium 
acetate buffer, $\mathrm{pH} 5$ without conjugate was also performed, the solution was incubated at $37{ }^{\circ} \mathrm{C}$ for $24 \mathrm{~h}$ and also analysed by HPLC-MS.

High performance liquid chromatography-mass spectrometry (HPLC-MS) was carried out on an Esquire 3000 + ion trap mass spectrometer (Bruker Daltonics, Bremen, Germany) equipped with a Jasco LC2000Plus HPLC system (Jasco Europe, Cremella, Italy). Compounds were separated on a Supelco Ascentis C18 column ( $3 \mu \mathrm{m}, 100 \AA$, 150 x $2.1 \mathrm{~mm}$; Sigma-Aldrich) using a gradient elution (0-5 min 2\% B, 5-26 min 2-90\% B, 26-27 $\min 90-100 \% \mathrm{~B}$ ) with the following eluents: $0.1 \%$ formic acid/water v/v (A eluent), $0.1 \%$ formic acid/acetonitrile-water $80: 20 \mathrm{v} / \mathrm{v}$ (B eluent). The flow rate was $0.2 \mathrm{~mL} / \mathrm{min}$ at ambient temperature. Spectra were recorded in positive ion mode in the 150-1200 m/z range (target mass set $500 \mathrm{~m} / \mathrm{z}$ ).

\subsection{Determination of intracellular antitubercular activity}

MonoMac6 cells were infected with M. tuberculosis $\mathrm{H}_{37} \mathrm{Rv}$ and the efficacy of the compounds against intracellular bacteria was determined [38, 42]. MonoMac6 human monocytic cell line was maintained in RPMI-1640 medium containing 10\% FCS, $2 \mathrm{mM} \mathrm{L-glutamine} \mathrm{and} 160 \mu \mathrm{g} / \mathrm{mL}$ gentamicin at $37{ }^{\circ} \mathrm{C}$ in $5 \%$ $\mathrm{CO}_{2}$ atmosphere. Prior to experiment, cells were cultured in a 24 -well plate for 24 hours $\left(2 \times 10^{5}\right.$ cells $/ 1 \mathrm{~mL}$ medium/well). Adherent cells were infected with M. tuberculosis $\mathrm{H}_{37} \mathrm{Rv}$ at a multiplicity of infection (MOI) of 10 for 4 hours. Non-phagocytized extracellular bacteria were removed and the culture was washed three times with serum free RPMI-1640. The infected monolayer was incubated for 1 day before antitubercular treatment. Infected cells were then treated with the compounds at 125 and $250 \mu \mathrm{M}$ final concentrations. After 3 days the treatment was repeated with fresh solution of the compounds for an additional 3 days. As control compound, isoniazid was used at $50 \mu \mathrm{g} / \mathrm{mL}(365 \mu \mathrm{M})$ concentration. Untreated cells were considered as negative control. After washing steps, in order to remove the compounds, infected cells were lysed with $2.5 \%$ sodium dodecyl sulfate solution. The CFU of M. tuberculosis $\mathrm{H}_{37} \mathrm{Rv}$ was enumerated on LöwensteinJensen solid media after 4 weeks of incubation. Experiments were repeated at least twice.

\section{Acknowledgements}

This work was financially supported by Hungarian Research Fund, OTKA K-104275 and the Czech Science Foundation project No. 17-27514Y. The authors thank Dr. Hedvig Medzihradszky-Schweiger for the amino acid analysis and Dr. Gitta Schlosser for the introduction into the practice of LC-MS.

\section{Conflict of Interest}

The authors declare no conflict of interest.

\section{Supporting Information description}

Schematic route of the synthesis of the tuftsin derivatives without side chain modification

Summary and chemical characterization of the synthesized (aminooxy)acetyl-tuftsin derivatives, their acetylated control analogues and fluorescently labelled analogues

Monitoring of the conjugation reaction of salicylanilide derivatives with tuftsin derivatives

Schematic figure of the salicylanilide-tuftsin conjugates

Chemical characterization of the salicylanilide-tuftsin conjugates

Stability study of salicylanilide-tuftsin conjugates

Lipophilicity profile of the salicylanilide derivatives and salicylanilide-peptide conjugates

Minimal inhibitory concentration (MIC) and colony forming unit (CFU) of the salicylanilides and the salicylanilide-tuftsin conjugates 
In vitro cytotoxic activity on $\mathrm{BMM} \Phi$ cells

Study of the $\mathrm{pH}$ dependence of the fluorescence intensity of the fluorescently labelled tuftsin derivatives Cellular uptake experiments of fluorescently labelled tuftsins

Membrane integrity studies by propidium iodide staining

Degradation study of SAL2-tuftsin conjugates in rat liver lysosomal homogenate

In vitro intracellular activity - lipophilicity comparison 


\section{List of captions}

Scheme 1. Synthesis of conjugable salicylanilides SAL1-3 (Ph-Cl: chlorobenzene).

Scheme 2. Schematic route of the synthesis of the tuftsin derivatives with side chain modification.

Scheme 3. (A) Conjugation of salicylanilide derivatives to (aminooxy)acetylated tuftsin derivatives and (B) the summarized schematic structure of the salicylanilide-tuftsin conjugates.

Figure 1. Retention time of parent salicylanilides, conjugable salicylanilides, salicylanilide amino acid derivatives (metabolites detected during lysosomal degradation) and salicylanilide-peptide conjugates. The calculated $\log \mathrm{P}$ value is indicated in the case of the parent salicylanilides, conjugable salicylanilides and metabolites using the program CS ChemOffice Ultra ver. 11.0 (CambridgeSoft, Cambridge, MA, USA). LogP was calculated for the amino acid derivatives with protonated amino group and/or deprotonated carboxylic group. The C-terminal of the peptides is in amide form, Ac = acetyl, retention time (Rt) was obtained on Exformma HPLC system; column: Agilent Zorbax SB-C18, $5 \mu \mathrm{m}, 4.6 \mathrm{mmx} 150 \mathrm{~mm}, 100 \AA$; gradient: 0 min $0 \%$ B, 5 min $0 \%$ B, $15 \min 60 \%$ B, 25 min $100 \%$ B; eluents: $0.1 \%$ TFA in water (A) and $0.1 \%$ TFA in acetonitrile-water (80:20, v/v) (B); flow rate: $1 \mathrm{~mL} / \mathrm{min}$; detection at $220 \mathrm{~nm}$.

Figure 2. Comparison of the $\mathrm{pH}$ dependence of the fluorescence intensity of the Cf-labelled tuftsin derivatives: (A) Cf-OT20 and (B) Cf-T5. (C) Comparison of the fluorescence intensity of the different Cflabelled tuftsin derivatives at $\mathrm{pH} 7$ at $50 \mu \mathrm{M}$, in $0.1 \mathrm{M}$ citric acid - $0.2 \mathrm{M} \mathrm{Na}_{2} \mathrm{HPO}_{4}$ buffer. The arrows indicate the compounds with lower fluorescence intensity than the average.

Figure 3. (A) Comparison of the cellular uptake on MonMac6 cells of the different fluorescently labelled tuftsin derivatives using flow cytometry at $200 \mu \mathrm{M}$ compound concentration ( $3 \mathrm{~h}$ incubation time). (B) Comparison of the cellular uptake of selected fluorescently labelled tuftsin derivatives at $8 \mu \mathrm{M}$ and $40 \mu \mathrm{M}$ compound concentrations ( $3 \mathrm{~h}$ incubation time).

Figure 4. Comparison of the cellular uptake $(3 \mathrm{~h})$ of selected fluorescently labelled tuftsin derivatives on MonoMac6 cells using fluorescent microscopy, bright field microscopic images and fluorescent microscopic images are shown. (A) Untreated control cells, (B) Cf-OT20, $200 \mu \mathrm{M}$, (C) SAL2-Aoa-OT20(4-Cf), $200 \mu \mathrm{M}$, (D) Cf-T5, $200 \mu \mathrm{M}$, (E) Cf-OT20(4-dec), $200 \mu \mathrm{M}$, (F) Cf-OT20(4-pal), $200 \mu \mathrm{M}$, (G) Cf-OT20(4-pal), 40 $\mu \mathrm{M}$, (H) Cf-OT20(4-pal), $8 \mu \mathrm{M}$.

Figure 5. Membrane integrity studies with propidium iodide (PI) staining of MonoMac6 cells after treatment $(3 \mathrm{~h}, 200 \mu \mathrm{M})$ with acetylated tuftsin derivatives with different fatty acid side chain modification using fluorescent microscopy, bright field microscopic images and fluorescent microscopic images are shown. (A) Untreated control cells, (B) Ac-OT20, (C) Ac-OT20(4-dec), (D) Ac-OT20(4-pal), (E) Ac-OT20(14-pal).

Figure 6. The detected cleavage sites during the degradation of SAL2-tuftsin conjugates in rat liver lysosomal homogenate.

Figure 7. The in vitro activity of the free salicylanilides and their peptide conjugates on M. tuberculosis $\mathrm{H}_{37} \mathrm{Rv}$ infected host cell model MonoMac6 cells. *(TKPR-OT10(SAL2)2 = TKPR-OT10(8-SAL2-Aoa; 13SAL2-Aoa))

Figure 8. Sorting of the salicylanilide-tuftsin conjugates according to their inhibition ability on the extracellular bacteria and their cytostatic effect on MonoMac6 cells. 
Figure 9. Map of the in vitro activity of the salicylanilide-tuftsin conjugates: correlation between the estimated internalization and the inhibition of intracellular bacteria. The efficacy on the extracellular bacteria and the cytostatic effect on MonoMac6 cells are also indicated.

Table 1. Antimycobacterial activity of the salicylanilides and the salicylanilide-tuftsin conjugates

Table 2. In vitro antimycobacterial activity of the previously published parent salicylanilide derivatives [9], their cytostatic activity $(24 \mathrm{~h})$ on MonoMac6 and HepG2 cells and selectivity indexes calculated for $M$. tuberculosis $\mathrm{H}_{37} \mathrm{Rv}$

Table 3. Cytostatic activity ( $24 \mathrm{~h})$ on MonoMac6 and HepG2 cells of SAL1-3, the salicylanilide-tuftsin conjugates, the control peptides and selectivity indexes calculated for M. tuberculosis $\mathrm{H}_{37} \mathrm{Rv}$

Table 4. Cytotoxic activity ( $3 \mathrm{~h}$ ) of the fluorescently labelled peptides on MonoMac6 cells determined by the data from the measurement with flow cytometer 


\section{References}

[1] Global tuberculosis report 2016, http://www.who.int/tb/publications/global_report/en/ (accessed 11-02-2017)

[2] D.E. Griffith, T. Aksamit, B.A. Brown-Elliott, A. Catanzaro, C. Daley, F. Gordin, S.M. Holland, R. Horsburgh, G. Huitt, M.F. Iademarco, M. Iseman, K. Olivier, S. Ruoss, C.F. von Reyn, R.J. Wallace, K. Winthrop, An official ATS/IDSA statement: Diagnosis, treatment, and prevention of nontuberculous mycobacterial diseases, Am. J. Respir. Crit. Care Med. 175 (2007) 367-416.

[3] R. Nessar, E. Cambau, J.M. Reyrat, A. Murray, B. Gicquel, Mycobacterium abscessus: a new antibiotic nightmare, J. Antimicrob. Chemother. 67 (2012) 810-818.

[4] B. Petrini, Mycobacterium abscessus: an emerging rapid-growing potential pathogen, APMIS 114 (2006) 319-328.

[5] F.P. Maurer, V.L. Bruderer, C. Ritter, C. Castelberg, G.V. Bloemberg, E.C. Böttger, Lack of antimicrobial bactericidal activity in Mycobacterium abscessus, Antimicrob. Agents Ch. 58 (2014) 3828-3836.

[6] M. Krátký, J. Vinšová, Salicylanilide ester prodrugs as potential antimicrobial agents - a review, Curr. Pharm. Des. 17 (2011) 3494-3505.

[7] J. Vinšová, A. Imramovsky, Salicylanilides: still a potential antibacterially active group, Ceska Slov. Farm. 53 (2004) 294.

[8] M. Krátký J. Vinšová, E. Novotná, J. Stolaříková, Salicylanilide pyrazinoates inhibit in vitro multidrug-resistant Mycobacterium tuberculosis strains, atypical mycobacteria and isocitrate lyase, Eur. J. Pharm. Sci. 53, (2014) 1-9.

[9] Zs. Baranyai, M. Krátký, J. Vinšová, N. Szabó, Zs. Senoner, K. Horváti, J. Stolař́iková, S. Dávid, Sz. Bősze, Combating highly resistant emerging pathogen Mycobacterium abscessus and Mycobacterium tuberculosis with novel salicylanilide esters and carbamates, Eur. J. Med. Chem. 101, (2015) 692-704.

[10] M.J. Macielag, J.P. Demers, S.A. Fraga-Spano, D.J. Hlasta, S.G. Johnson, R.M. Kanojia, R.K. Russell, Z. Sui, M.A. Weidner-Wells, H. Werblood, B.D. Foleno, R.M. Goldschmidt, M.J. Loeloff, G.C. Webb, J.F. Barrett, Substituted salicylanilides as inhibitors of two-component regulatory systems in bacteria, J. Med. Chem. 41 (1998) 2939-2945.

[11] M. Krátký, M. Volková, E. Novotná, F. Trejtnar, J. Stolaříková, J. Vinšová, Synthesis and biological activity of new salicylanilide $N, N$-disubstituted carbamates and thiocarbamates, Bioorg. Med. Chem. 22 (2014) 4073-4082.

[12] M. Krátký, J. Vinšová, Advances in mycobacterial isocitrate lyase targeting and inhibitors, Curr. Med. Chem. 19 (2012) 6126-6137.

[13] M. Krátký, E. Novotná, S. Saxena, P. Yogeeswari, D. Sriram, M. Švarcová, J. Vinšová, Salicylanilide diethyl phosphates as potential inhibitors of some mycobacterial enzymes, The Sci. World J. (2014) article ID 703063, http://dx.doi.org/10.1155/2014/703053

[14] M. Krátký, J. Vinšová, E. Novotná, V. Wsól, V. Ulmann, J. Stolaříková, S. Fernandes, S. Bhat, J.O. Liu, Salicylanilide derivatives block Mycobacterium tuberculosis through inhibition of isocitrate lyase and methionine aminopeptidase, Tuberculosis 92 (2012) 434-439.

[15] S. Majumdar, S.K. Basu, Killing of intracellular Mycobacterium tuberculosis by receptor-mediated drug delivery, Antimicrob. Agents Chemother. 35 (1991) 135-140.

[16] K. Horváti, G. Mező, N. Szabó, F. Hudecz, Sz. Bősze, Peptide conjugates of therapeutically used antitubercular isoniazid-design, synthesis and antimycobacterial effect, J. Pept. Sci. 15 (2009) 385-391.

[17] A.A. Amoscato, P.J. Davies, G.F. Babcock, K. Nishioka, Receptor-mediated internalization of tuftsin, Ann. N.Y. Acad. Sci. 419 (1983) 114-134.

[18] P. Gottlieb, E. Hazum, E. Tzehoval, M Feldman, S. Segal, M. Fridkin, Receptor-mediated endocytosis of tuftsin by macrophage cells, Biochem. Biophys. Res. Commun. 119 (1984) 203-211.

[19] A.K. Agrawal, C.M. Gupta, Tuftsin-bearing liposomes in treatment of macrophage-based infections, Adv. Drug Delivery Rev. 41 (2000) 135-146.

[20] Z. Barshavit, R. Goldman, Y. Stabinsky, M. Fridkin, Tuftsin-macrophage interaction - specific binding and augmentation of phagocytosis, J. Cell. Physiol. 100 (1979) 55-62.

[21] P. Gottlieb, Y. Stabinsky, Y. Hiller, A. Beretz, E. Hazum, E. Tzehoval, M. Feldman, S. Segal, V. Zakuth, Z. Spirer, M. Fridkin, Tuftsin receptors, Ann. N. Y. Acad. Sci. 419 (1983) 93-106. 
[22] V.A. Najjar, K. Nishioka, "Tuftsin": a natural phagocytosis stimulating peptide, Nature 228 (1970) 672-673.

[23] K. Nishioka, A. Constantopoulos, P.S. Satoh, V.A. Najjar, The characteristics, isolation and synthesis of the phagocytosis stimulating peptide tuftsin, Biochem. Biophys. Res. Commun. 47 (1972) 172-179.

[24] B.R. Zetter, N. Rasmussen, L. Brown, An in vivo assay for chemoattractant activity, Lab. Invest. 53 (1985) 362368.

[25] K. Lukács, G. Szabó, I. Sonkoly, E. Végh, J. Gács, M. Szekerke, G. Szegedi, Stimulating effect of tuftsin and its analogs on the defective monocyte chemotaxis in systemic lupus erythematosus, Immunopharmacology 7 (1984) 171178.

[26] G. Mezö, A. Kalászi, J. Reményi, Zs. Majer, A. Hilbert, O. Láng, L. Kőhidai, K. Barna, D. Gaál, F. Hudecz, Synthesis, conformation, and immunoreactivity of new carrier molecules based on repeated tuftsin-like sequence, Biopolymers 73 (2004) 645-56.

[27] K.B. Bai, O. Láng, E. Orbán, R. Szabó, L. Kőhidai, F. Hudecz, G. Mező, Design, synthesis, and in vitro activity of novel drug delivery systems containing tuftsin derivatives and methotrexate, Bioconjug. Chem. 19 (2008) 2260-2269.

[28] M. Fridkin, V.A. Najjar, Tuftsin: its chemistry, biology, and clinical potential, Crit. Rev. Biochem. Mol. Biol. 24 (1989) 1-40.

[29] I.Z. Siemion, A. Kluczyk, Tuftsin: on the 30-year anniversary of Victor Najjar's discovery, Peptides 20 (1999) 645-674.

[30] M. Fridkin, P. Gottlieb, Tuftsin, Thr-Lys-Pro-Arg. Anatomy of an immunologically active peptide, Mol. Cell. Biochem. 41 (1981) 73-97.

[31] A. Malina, Y. Shai, Conjugation of fatty acids with different lengths modulates the antibacterial and antifungal activity of a cationic biologically inactive peptide, Biochem. J. 390 (2005) 695-702.

[32] F. Rabanal, A. Grau-Campistany, X. Vila-Farrés, J. Gonzalez-Linares, M. Borràs, J. Vila, A. Manresa, Y. Cajal, A bioinspired peptide scaffold with high antibiotic activity and low in vivo toxicity, Sci. Rep. 5 (2015) Article number: 10558, doi:10.1038/srep10558

[33] Cs.B. Pénzes, D. Schnöller, K. Horváti, Sz. Bősze, G. Mező, É. Kiss, Membrane affinity of antituberculotic drug conjugate using lipid monolayer containing mycolic acid, Colloids Surf. A Physicochem. Eng. Asp. 413 (2012) 142-148

[34] H. Okuyama, T. Kankura, S. Nojima, Positional distribution of fatty acids in phospholipids from mycobacteria, $J$. Biochem. 61 (1967) 732-737.

[35] F.P. Tally, M.F. DeBruin, Development of daptomycin for Gram-positive infections, J. Antimicrob. Chemother. 46 (2000) 523-526.

[36] N.E. Allen, J.N. Hobbs, W.E. Alborn, Inhibition of peptidoglycan biosynthesis in Gram-positive bacteria by LY146032, Antimicrob. Agents Chemother. 31 (1987) 1093-1099.

[37] K. Horváti, G. Mező, N. Szabó, F. Hudecz, Sz. Bősze, Peptide conjugates of therapeutically used antitubercular isoniazid - design, synthesis and antimycobacterial effect, J. Pept. Sci. 15 (2009) 385-391.

[38] K. Horváti, B. Bacsa, N. Szabó, S. Dávid, G. Mező, V. Grolmusz, B. Vértessy, F. Hudecz, Sz. Bősze, Enhanced cellular uptake of a new, in silico identified antitubercular candidate by peptide conjugation, Bioconjug. Chem. 23 (2012) 900-907.

[39] Á. Ábrahám, Zs. Baranyai, G. Gyulai, E. Pári, K. Horváti, Sz. Bősze, É. Kiss, Comparative analysis of new peptide conjugates of antitubercular drug candidates - model membrane and in vitro studies, Colloid. Surface. B., 147 (2016) 106-115.

[40] É. Kiss, D. Schnöller, K. Pribranská, K. Hill, Cs.B. Pénzes, K. Horváti, Sz. Bősze, Nanoencapsulation of antitubercular drug isoniazid and its lipopeptide conjugate, J. Dispers. Sci. Technol. 32 (2011) 1728-1734.

[41] K. Horváti, B. Bacsa, N. Szabó, K. Fodor, G. Balka, M. Rusvai, É. Kiss, G. Mező, V. Grolmusz, B. Vértessy, F. Hudecz, Sz. Bősze, Antimycobacterial activity of peptide conjugate of pyridopyrimidine derivative against Mycobacterium tuberculosis in a series of in vitro and in vivo models, Tuberculosis (Edinb.) 95 (2015) S207-211. 
[42] K. Horváti, B. Bacsa, É. Kiss, G. Gyulai, K. Fodor, G. Balka, M. Rusvai, E. Szabó, F. Hudecz, Sz. Bősze, Nanoparticle encapsulated lipopeptide conjugate of antitubercular drug isoniazid: in vitro intracellular activity and in vivo efficacy in a Guinea pig model of tuberculosis, Bioconjug. Chem. 25 (2014) 2260-2268.

[43] N.J. Bump, J. Lee, M. Wleklik, J. Reichler, V.A. Najjar, Isolation and subunit composition of tuftsin receptor, Proc. Natl. Acad. Sci. USA 83 (1986) 7187-7191.

[44] J. Shao, J.P. Tam, Unprotected peptides as building blocks for the synthesis of peptide dendrimers with oxime, hydrazone, and thiazolidine linkages, J. Am. Chem. Soc. 117 (1995) 3893-3899.

[45] J. Kopecek, P. Kopecková, T. Minko, Z.-R. Lu, HPMA copolymer-anticancer drug conjugates: design, activity, and mechanism of action, Eur. J. Pharm. Biopharm. 50 (2000) 61-81.

[46] M. Krátký, J. Vinšová, V. Buchta, K. Horváti, Sz. Bősze, J. Stolaříková, New amino acid esters of salicylanilides active against MDR-TB and other microbes, Eur. J. Med. Chem. 45 (2010) 6106-6113.

[47] B.W. Bycroft, W.C. Chan, S.R. Chhabra, N.D.J. Hone, A novel lysine-protecting procedure for continuous flow solid phase synthesis of branched peptides, J. Chem. Soc., Chem. Commun. 9 (1993) 778-779.

[48] C. Giaginis, A. Tsantili-Kakoulidou, Alternative measures of lipophilicity: from octanol-water partitioning to IAM retention, J. Pharm. Sci. 97 (2008) 2984-3004.

[49] E. Rutkowska, K. Pajak, K. Jóźwiak, Lipophilicity - methods of determination and its role in medicinal chemistry, Acta Pol. Pharm. 70 (2013) 3-18.

[50] J-L. Fauchère, Lipophilicity in Peptide Chemistry and Peptide Drug Design, in Lipophilicity in Drug Action and Toxicology (eds V. Pliška, B. Testa and H. van de Waterbeemd), Wiley-VCH Verlag GmbH, Weinheim, Germany, 1996, pp. 355-373.

[51] A.I. Fernández-Llamazares, J. Adan, F. Mitjans, J. Spengler, F. Albericio, Tackling lipophilicity of peptide drugs: replacement of the backbone N-methyl group of cilengitide by N-oligoethylene glycol (N-OEG) chains, Bioconjug. Chem. 25 (2014) 11-17.

[52] H.W. Ziegler-Heitbrock, E. Thiel, A. Fütterer, V. Herzog, A. Wirtz, G. Riethmüller, Establishment of a human cell line (Mono Mac 6) with characteristics of mature monocytes, Int. J. Cancer 41 (1988) 456-461.

[53] Z. Bar-Shavit, I. Bursuker, R. Goldman, Functional tuftsin binding sites on macrophage-like tumor line P388D1 and on bone marrow cells differentiated in vitro into mononuclear phagocytes, Mol. Cell. Biochem. 30 (1980) 151-5.

[54] C. Riccardi, I. Nicoletti, Analysis of apoptosis by propidium iodide staining and flow cytometry, Nat. Protoc. 1 (2006) 1458-1461.

[55] J.A. Mindell, Lysosomal acidification mechanisms, Annu. Rev. Physiol. 74 (2012) 69-86.

[56] E. Orbán, G. Mezö, P. Schlage, G. Csík, Z. Kulić, P. Ansorge, E. Fellinger, H.M. Möller, M. Manea, In vitro degradation and antitumor activity of oxime bond-linked daunorubicin-GnRH-III bioconjugates and DNA-binding properties of daunorubicin-amino acid metabolites, Amino Acids 41 (2011) 469-483.

[57] J.S. Friedland, R.J. Shattock, G.E. Griffin, Phagocytosis of Mycobacterium tuberculosis or particulate stimuli by human monocytic cells induces equivalent Monocyte Chemotactic Protein-1 gene expression, Cytokine 5 (1993) 150156.

[58] W. Erl, C. Weber, C. Wardemann, P.C. Weber, Adhesion properties of Mono Mac 6, a monocytic cell line with characteristics of mature human monocytes, Atherosclerosis 113 (1995) 99-107.

[59] R. Fischer. O. Mader, G. Jung, R. Brock, Extending the applicability of carboxyfluorescein in solid-phase synthesis, Bioconjug. Chem. 14 (2003) 653-660.

[60] L. Sula, Who co-operative studies on a simple culture technique for isolation of mycobacteria. 1. Preparation, lyophilization and reconstitution of a simple semi-synthetic concentrated liquid medium - culture technique - growth pattern of different mycobacteria, Bull. World Health Organ. 29 (1963) 589-606.

[61] L. Sula, T.K. Sundaresan, Who-co-operative studies on a simple culture technique for isolation of mycobacteria. 2. Comparison of efficacy of lyophilized liquid medium with that of Löwenstein-Jensen (L-J) medium. Bull. World Health Organ. 29 (1963) 607-625. 
[62] R. Szabó, R., L. Peiser, A. Plüddemann, Sz. Bősze, S. Heinsbroek, S. Gordon, F. Hudecz, Uptake of branched polypeptides with poly[L-Lys] backbone by bone-marrow culture-derived murine macrophages: the role of the class A scavenger receptor, Bioconjug. Chem. 16 (2005) 1442-1450. 